\title{
A Comprehensive Revision of the U.S. Monetary Services (Divisia) Indexes
}

\author{
Richard G. Anderson and Barry E. Jones
}

\begin{abstract}
The authors introduce a comprehensive revision of the Divisia monetary aggregates for the United States published by the Federal Reserve Bank of St. Louis, referred to as the Monetary Services Indexes (MSI). These revised MSI are available at five levels of aggregation, including a new broad level of aggregation that includes all of the assets currently reported on the Federal Reserve's H.6 statistical release. Several aspects of the new MSI differ from those previously published. One such change is that the checkable and savings deposit components of the MSI are now adjusted for the effects of retail sweep programs, beginning in 1994. Another change is that alternative MSI are provided using two alternative benchmark rates. In addition, the authors have simplified the procedure used to construct the own rate of return for small-denomination time deposits and have discontinued the previous practice of applying an implicit return to some or all demand deposits. The revised indexes begin in 1967 rather than 1960 because of data limitations.
\end{abstract} (JEL C43, C82, E4, E50)

Federal Reserve Bank of St. Louis Review, September/October 2011, 93(5), pp. 325-59.

Money is necessary to the carrying on of trade. For where money fails, men cannot buy, and trade stops.

一John Locke, Further Considerations Concerning Raising the Value of Money (1696, p. 319; quoted by Vickers, 1959)

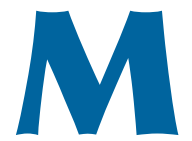

oney plays a crucial role in the economy because the purchase and sale of goods and services is settled in what economists refer to as "medium of exchange." Forward-looking consumers and firms determine their desired quantities of medium of exchange at approximately the same time as they (i) form expectations of future income and expenditure and (ii) make decisions regarding desired quantities of financial and nonfinancial assets. The financial assets selected by consumers and firms may be separated into two groups. Some assets, including currency and checkable bank deposits, are innately medium of exchange- that is, usable in the purchase and sale of goods and serviceswhile others cannot be used until converted to medium of exchange. ${ }^{1}$ Generally, monetary assets that differ in terms of their potential usefulness as medium of exchange also differ in their own rates of return. Barnett (1980) developed the concept and theory of monetary index numbers,

1 There are exceptions, of course. Bank checks, for example, are not accepted by all merchants. Even for currency, there are exceptions (see Twain, 1996). More seriously, currency issued by a sovereign country often is not accepted in other countries; for a discussion of monetary index numbers defined across currencies, see Barnett (2007).

Richard G. Anderson is an economist and vice president at the Federal Reserve Bank of St. Louis and visiting professor, Management School, University of Sheffield (U.K.). Barry E. Jones is associate professor of economics at Binghamton University-State University of New York. The authors thank Yang Liu and Esha Singha for research assistance and Barry Cynamon, Livio Stracca, and Jim Swofford for helpful comments on an earlier draft. Anderson thanks the research department of the Federal Reserve Bank of Minneapolis for their hospitality during the completion of this analysis. Jones thanks the Federal Reserve Bank of St. Louis and the department of economics at Lund University for their hospitality during several visits.

(C) 2011, The Federal Reserve Bank of St. Louis. The views expressed in this article are those of the author(s) and do not necessarily reflect the views of the Federal Reserve System, the Board of Governors, or the regional Federal Reserve Banks. Articles may be reprinted, reproduced, published, distributed, displayed, and transmitted in their entirety if copyright notice, author name(s), and full citation are included. Abstracts, synopses, and other derivative works may be made only with prior written permission of the Federal Reserve Bank of St. Louis. 
which he referred to as "Divisia monetary aggregates.” Divisia aggregates measure, in a method consistent with intertemporal microeconomic theory, the aggregate flow of monetary services derived by consumers and firms from a collection of monetary assets with different characteristics and different rates of return. Underlying Divisia monetary aggregates is the concept of the user cost of a monetary asset, which is a function of the interest forgone by holding a specific asset rather than an alternative asset that does not provide any monetary services and earns a higher rate of return (referred to as the "benchmark rate"). The close connection in microeconomic theory between monetary index numbers and agents' anticipated income and expenditure suggests that monetary index numbers should be more closely related to economic activity than conventional simple sum monetary aggregates (see, for example, Hancock, 2005; Barnett and Chauvet, 2011; Barnett, forthcoming).

\section{THE MACROECONOMICS OF MONETARY AGGREGATION}

This article discusses how to construct monetary index numbers (Divisia monetary aggregates) for the United States. ${ }^{2}$ For the most part, we do not address when or why such measurement and aggregation might be desirable, which is controversial to some extent among macroeconomists. The extant principal body of current macroeconomic analysis widely uses the concept of an aggregate measure of money and distinctly separates "money" from other assets, financial and nonfinancial. ${ }^{3}$ Typically, macroeconomists define "money" as financial assets that either are medium of exchange or convertible to medium of exchange at de minimus cost. Demand for such assets is

\footnotetext{
2 Throughout this analysis, the term "monetary assets" refers to those financial assets that can provide "monetary services" during the period-that is, they can serve as a medium of exchange. Some assets (currency, checkable deposits) are immediately medium of exchange. Other assets have the standby capability to act as medium of exchange if there exist markets that allow the assets to be exchanged for medium of exchange when need be, either by means of a sale or use as collateral.

3 Walsh (2010) is a comprehensive recent textbook treatment.
}

motivated in a macroeconomic model by either cash-in-advance or shopping-time constraints or a money-in-the-utility (or production) function specification. ${ }^{4}$ Models differ, however, regarding whether a household or firm might replenish a depleted stock of money during the current period by selling (or using as collateral) its nonmonetary assets. If such a mechanism is permitted, the correct definition of a monetary aggregate for macroeconomic analysis depends on assumptions regarding the liquidity of those assets that are not medium of exchange.

A complementary, but alternative, line of thought argues that (i) the concept of a monetary aggregate in macroeconomics is unnecessary and misleading and (ii) models should focus on the functions of financial assets, including as a medium of exchange and an intertemporal store of value. Monetary aggregates, for example, have no role in the class of recent search-based macroeconomic models that Stephen Williamson and Randall Wright have labeled "New Monetarist economics."5 Although the exchange of goods and services is fundamental in such models, the role of an asset as a medium of exchange is unimportant because the models (implicitly or explicitly) assume a transformation technology such that (almost) any asset can fulfill the functional role of medium of exchange-that is, all assets are liquid. For example, Williamson and Wright (2010, p. 294) write:

Note as well that theory provides no particular rationale for adding up certain public and private liabilities (in this case currency and bank deposits), calling the sum money, and attaching some special significance to it. Indeed, there are equilibria in the model where currency and bank deposits are both used in some of the same transactions, both bear the same rate of return, and the stocks of both turn over once each period. Thus, Friedman, if he were alive, might think he had good reason to call the sum of currency and bank deposits money and proceed from there. But what the model tells us is that public and private liquidity play

\footnotetext{
4 A classic analysis is King and Plosser (1984).

5 Williamson and Wright $(2010,2011)$.
} 
quite different roles. In reality, many assets are used in transactions, broadly defined, including Treasury bills, mortgage-backed securities, and mutual fund shares. We see no real purpose in drawing some boundary between one set of assets and another, and calling members of one set money.

New Monetarist-style models seek to illustrate how a demand for monetary services arises as a result of optimizing behavior by households and firms. To do so, generally speaking, the models assert that a shortage of medium of exchange is costly in the sense that trades do not occur that otherwise would be Pareto welfare-improving. In such models, most financial assets are treated as near-perfect substitutes; the role of the transaction costs entailed in exchanging an asset that does not furnish medium of exchange services for one that does is secondary, such that even mortgage-backed securities furnish medium of exchange (that is, monetary) services.

In a related recent analysis that addresses neither the wisdom nor the necessity of monetary aggregation, Holmström and Tirole (2011) ask if transaction costs and "sudden stops" in financial markets explain why households and firms choose to hold larger quantities of highly liquid assets than is suggested by models with de minimus asset-market transaction costs. They note: "While some forms of equity, such as private equity, may not be readily sold at a 'fair price,' many longterm securities are traded on active organized exchanges...liquidating one's position...can be performed quickly and at low transaction costs" (p. 1). Their analysis implies that not all financial assets are perfect substitutes due to the risks that (i) market trading might suddenly halt, (ii) differential user costs can arise in the solution to the optimization problem facing households and firms, and (iii) such differential user costs reflect the differing amounts of monetary services furnished by the assets.

\section{THE ROLE OF THE FEDERAL RESERVE BANK OF ST. LOUIS}

The Federal Reserve Bank of St. Louis has published monetary index numbers (initially referred to as Divisia monetary aggregates and, later, as Monetary Services Indexes [MSI]) for two decades, beginning with Thornton and Yue (1992) and continuing with Anderson, Jones, and Nesmith (1997a,b,c) and Anderson and Buol (2005). Publication of the most recent series was suspended in March 2006 when certain necessary data became unavailable.

In this paper, we introduce a comprehensive revision of the MSI constructed at five levels of aggregation: MSI-M1, MSI-M2, MSI-M2M, MSIMZM, and MSI-ALL. MSI-M1 and MSI-M2 are constructed, respectively, over the same components included in the Federal Reserve Board's M1 and M2 monetary aggregates. MSI-ALL is constructed over all assets currently reported on the Federal Reserve Board's H.6 statistical release (the components of M2 plus institutional money market mutual funds [MMMFs]) and is the broadest level of aggregation that currently can be constructed from available data. Finally, MSI-M2M and MSI-MZM are zero-maturity indexes (i.e., they exclude small-denomination time deposits). One change to the indexes is the adjustment of checkable and savings deposit components of the MSI for the effects of retail sweep programs, beginning in 1994.

Several changes have been made to the user costs of the components. Among these, we discontinued the previous practice of assigning an implicit return to some or all demand deposits and simplified the procedure used to construct the own rate for small-denomination time deposits. We also improved measures of savings and small time deposit rates in the Regulation Q era; as a consequence, the start date of the MSI has been changed from 1960 to 1967. Finally, the MSI are now constructed using two different benchmark rates. Our preferred benchmark rate is the maximum taken over the own rates of the components of MSI-ALL and a set of short-term money market rates (referred to in the literature as the "upper envelope") plus a small liquidity premium. The alternative benchmark rate is the larger of our preferred benchmark rate and the Baa bond yield. Previous practice had been to simply include the Baa bond yield in the upper envelope.

The remainder of the paper is organized as follows. The next section provides a brief over- 
view of the theory behind the MSI. We then describe the MSI and their changes relative to Anderson, Jones, and Nesmith (1997c). Next, we examine the empirical properties of the MSI, emphasizing the time-series behavior of the indexes. The final section offers some conclusions.

\section{MONETARY AGGREGATION AND INDEX NUMBER THEORY}

This section briefly reviews the economic theory of monetary aggregation. Readers interested primarily in the data may skip this section without loss of continuity; readers seeking a more comprehensive survey might consult Anderson, Jones, and Nesmith (1997b).

The user cost of a monetary asset, defined as the interest income forgone by holding a specific financial asset rather than a higher-yielding asset that does not provide monetary services, plays an essential role in monetary aggregation theory. Divisia monetary aggregates are chain-weighted superlative indexes constructed over the quantities and user costs of selected sets of monetary assets. The earliest Divisia aggregates for the United States were constructed at the Federal Reserve Board through the mid-1980s by Barnett, Offenbacher, and Spindt (1981) and, later, by Farr and Johnson (1985), who introduced the descriptive label "Monetary Services Indexes."6

\section{Background}

Barnett $(1978,1980)$ developed Divisia monetary aggregates from aggregation and index number theory; see Barnett and Serletis (2000) for a comprehensive overview. The basic ideas can be illustrated with a simple money-in-the-utility function model. In each period $t$, a representative consumer is assumed to maximize lifetime utility:

$$
\sum_{s=t}^{\infty} \beta^{s-t} u\left(\mathrm{c}_{s}, \mathrm{~m}_{s}\right)
$$

where $\mathrm{C}_{s}$ denotes a vector of quantities of a set of nonmonetary goods and services and $\mathrm{m}_{s}$ denotes

6 Divisia money measures for the United Kingdom have been maintained by the Bank of England since the early 1990s (see Fisher, Hudson, and Pradhan, 1993, and Hancock, 2005). a vector of real stocks of a set of monetary assets. The budget constraints are given by

$$
\begin{aligned}
& \mathrm{p}_{s} \cdot \mathrm{c}_{s}=p_{s-1}^{*} b_{s-1}\left(1+R_{s}\right)-p_{s}^{*} b_{s} \\
& +\sum_{n=1}^{N}\left[p_{s-1}^{*} m_{n, s-1}\left(1+r_{n, s}\right)-p_{s}^{*} m_{n, s}\right]+Y_{s}
\end{aligned}
$$

for all $s \geq t$, where $b_{s}$ denotes the real stock of a benchmark asset that does not enter into the utility function, $Y_{s}$ represents nominal income not due to asset holdings, $p_{s}^{*}$ is a price index used to convert nominal stocks to real terms, $\mathrm{p}_{s}$ is the price vector for the nonmonetary goods and services, $R_{s}$ is the nominal rate of return on the benchmark asset, and $r_{n, s}$ is the nominal own rate of return (possibly zero) for the $n$th monetary asset.

The user cost of each monetary asset is derived from the above maximization. Barnett (1978) derived the formula for the user cost of a monetary asset by combining individual-period budget constraints into a single lifetime budget constraint. When optimizing in period $t$, currentperiod real money balances, $m_{n, t}$, are multiplied in the lifetime budget constraint by $\pi_{n, t}=p_{t}^{*} u_{n, t}$, where

$$
u_{n, t}=\frac{R_{t}-r_{n, t}}{1+R_{t}} .
$$

Consequently, $\pi_{n, t}$ is the user cost for $m_{n, t} \cdot{ }^{7}$ Usually, $\pi_{n, t}$ is referred to as the "nominal user cost" and $u_{n, t}$ as the corresponding "real user cost" (Barnett, 1987, p. 118). In an alternative derivation, Donovan (1978, pp. 682-86) obtained the same expression by applying the user cost formula for a durable good to interest-bearing monetary assets. ${ }^{8}$ Diewert (1974, p. 510) did the same for non-interest-bearing assets.

\footnotetext{
7 More generally, when optimizing in period $t$, the (discounted) user cost for $m_{n, s}(s \geq t+1)$ is given by$$
p_{s}^{*} \frac{R_{s}-r_{n, s}}{\left(1+R_{t}\right)\left(1+R_{t+1}\right) \cdots\left(1+R_{s}\right)} .
$$

See Barnett (1978) for further discussion. Diewert (1974) provides analogous expressions for durable goods.

8 The user cost of a durable good is the difference between the purchase price of a unit of the good and the present value of the sale price one period later (adjusted for depreciation). Donovan's argument is as follows: Holding $p_{t}^{*}$ dollars of a monetary asset in period $t$ is equivalent to holding one real dollar of the monetary asset.
} 
A key property in aggregation and index number theory is weak separability. In the present context, monetary assets are weakly separable from the other goods and services included in the utility function if

$$
u(\mathrm{c}, \mathrm{m}) \equiv U[\mathrm{c}, V(\mathrm{~m})],
$$

where $U$ is strictly increasing in $V$ (see Varian, 1983, p. 104). Under weak separability, utility maximization in period $t$ implies that the vector of real money balances, $\mathrm{m}_{t}$, chosen in that period maximizes the sub-utility function, $V(\mathrm{~m})$, subject to the budget constraint, $\pi_{t} \cdot \mathrm{m}=\pi_{t} \cdot \mathrm{m}_{t}$, where $\pi_{t}$ is a vector of nominal user costs. ${ }^{9}$

Chain-weighted superlative indexes constructed from data on the quantities of monetary assets and their user costs can be used to measure how $V\left(\mathrm{~m}_{t}\right)$ evolves over time; here, we provide an overview (see the appendix for details). Specifically, the MSI are based on the superlative Törnqvist-Theil formula. The chain-weighted Törnqvist-Theil monetary quantity index is

$$
V_{t}=V_{t-1} \prod_{n=1}^{N}\left(\frac{m_{n, t}}{m_{n, t-1}}\right)^{\frac{W_{n, t}+W_{n, t-1}}{2}},
$$

where

$$
w_{n, t}=\frac{\pi_{n, t} m_{n, t}}{\sum_{i=1}^{N} \pi_{i, t} m_{i, t}}
$$

is the expenditure share for the $n$th monetary asset for period $t$. The index has the attractive property that its log difference is a weighted average of the log differences of its components:

Thus, the purchase price of a real dollar of the monetary asset is $p_{t}^{*}$ and the sale price of a real dollar of the asset one period later is $p_{t+1}^{*}$. If the asset earns interest, holding $p_{t}^{*}$ dollars of the asset for one period results in $p_{t}^{*}\left(1+r_{n, t}\right) / p_{t+1}^{*}$ real dollars of the asset one period later. Consequently, the user cost of the monetary asset is

$$
p_{t}^{*}-p_{t+1}^{*} \frac{p_{t}^{*}\left(1+r_{n, t}\right)}{p_{t+1}^{*}\left(1+R_{t}\right)}=p_{t}^{*} \frac{R_{t}-r_{n, t}}{1+R_{t}}=\pi_{n, t} .
$$

${ }^{9}$ Barnett (1982) emphasizes weak separability in choosing the components of a monetary aggregate. Varian $(1982,1983)$ derived necessary and sufficient conditions for a dataset to be consistent with utility maximization and weak separability. A number of studies have applied tests of these conditions to determine if specific groupings of monetary assets are weakly separable. For recent examples, see Jones, Dutkowsky and Elger (2005), Drake and Fleissig (2006), and Elger et al. (2008).

$$
\begin{aligned}
& \ln \left(V_{t}\right)-\ln \left(V_{t-1}\right)= \\
& \sum_{n=1}^{N}\left(\frac{w_{n, t}+w_{n, t-1}}{2}\right)\left[\ln \left(m_{n, t}\right)-\ln \left(m_{n, t-1}\right)\right] .
\end{aligned}
$$

Barnett (1980) interpreted the Törnqvist-Theil index as a discrete-time approximation of the continuous-time Divisia index, which is the origin of the term Divisia monetary aggregate. As he emphasized, in continuous time the Divisia index is exact for any linearly homogeneous utility function. ${ }^{10}$

\section{The MSI and Their Dual User Cost Indexes}

The published St. Louis MSI are constructed from nominal rather than real monetary asset quantities and, in that sense, are nominal monetary index numbers; corresponding real MSI can be obtained by dividing the nominal MSI by a price index. We also publish real user cost indexes for the various MSI that are suitable for use in empirical work as the opportunity costs of those MSI. The real user cost indexes can be multiplied by a price index to obtain corresponding nominal user cost indexes. This is analogous to the relationship between real and nominal user costs of individual monetary assets as discussed above.

Specifically, let $p_{t}^{*}$ denote a price index, and let $M_{n, t}$ and $m_{n, t}$ denote the nominal and real quantities, respectively, of the $n$th monetary asset-that is, $m_{n, t}=M_{n, t} / p_{t}^{*}$. Let $u_{n, t}$ be the corresponding real user cost, which does not depend on the price index. The corresponding nominal user cost is $\pi_{n, t}=p_{t}^{*} u_{n, t}$. The published nominal MSI are constructed using nominal monetary asset quantities as follows:

$$
\operatorname{MSI}_{t}=\operatorname{MSI}_{t-1} \prod_{n=1}^{N}\left(\frac{M_{n, t}}{M_{n, t-1}}\right)^{\frac{W_{n, t}+W_{n, t-1}}{2}} .
$$

\footnotetext{
${ }^{10}$ If $\mathrm{m}_{t}$ maximizes $V(\mathrm{~m})$ subject to the budget constraint $\pi_{t} \cdot \mathrm{m}=$ $\pi_{t} \cdot \mathrm{m}_{t}$ for all $t$ and $V(\mathrm{~m})$ is linearly homogeneous, then in the continuous-time case$$
\frac{d \ln \left(V_{t}\right)}{d t}=\frac{d \ln \left(V\left(\mathrm{~m}_{t}\right)\right)}{d t}=\sum_{n=1}^{N} w_{n, t} \frac{d \ln \left(m_{n, t}\right)}{d t},
$$

which corresponds to the continuous-time Divisia quantity index (see Barnett, 1987, p. 141). 
The expenditure shares can be computed from nominal monetary asset quantities and real user costs, since

$$
w_{n, t}=\frac{\pi_{n, t} m_{n, t}}{\sum_{i=1}^{N} \pi_{i, t} m_{i, t}}=\frac{u_{n, t} m_{n, t}}{\sum_{i=1}^{N} u_{i, t} m_{i, t}}=\frac{u_{n, t} M_{n, t}}{\sum_{i=1}^{N} u_{i, t} M_{i, t}} .
$$

Real MSI are obtained by dividing the nominal MSI by the price index $p_{t}^{*}$. This is equivalent to constructing the MSI using real quantities of individual assets when the real quantities are defined using the same price index-that is, for all $n, m_{n, t}=M_{n, t} / p_{t}^{*}$, since

$$
\begin{aligned}
& \frac{M S I_{t} / p_{t}^{*}}{M S I_{t-1} / p_{t-1}^{*}}=\prod_{n=1}^{N}\left(\frac{M_{n, t} / p_{t}^{*}}{M_{n, t-1} / p_{t-1}^{*}}\right)^{\frac{W_{n, t}+W_{n, t-1}}{2}}= \\
& \prod_{n=1}^{N}\left(\frac{m_{n, t}}{m_{n, t-1}}\right)^{\frac{W_{n, t}+W_{n, t-1}}{2}}=\frac{v_{t}}{v_{t-1}} \cdot{ }^{11}
\end{aligned}
$$

Let $\Pi_{t}$ and $U_{t}$ denote, respectively, the nominal and real user cost indexes for a specific MSI. The user cost index, $U_{t}$, is computed via factor reversal with its corresponding nominal MSI:

$$
\begin{aligned}
& \frac{U_{t} M I_{t}}{U_{t-1} M S I_{t-1}}=\frac{\sum_{n=1}^{N} u_{n, t} M_{n, t}}{\sum_{n=1}^{N} u_{n, t-1} M_{n, t-1}}= \\
& \frac{\sum_{n=1}^{N} \pi_{n, t} M_{n, t} / p_{t}^{*}}{\sum_{n=1}^{N} \pi_{n, t-1} M_{n, t-1} / p_{t-1}^{*}}=\frac{\sum_{n=1}^{N} \pi_{n, t} m_{n, t}}{\sum_{n=1}^{N} \pi_{n, t-1} m_{n, t-1}} .
\end{aligned}
$$

The nominal user cost index for the same MSI is $\Pi_{t}=p_{t}^{*} U_{t}$. Because nominal MSI can be converted to real MSI via division by a price index, it follows that nominal user cost indexes satisfy factor reversal with the corresponding real MSI:

$$
\begin{gathered}
\frac{\Pi_{t} V_{t}}{\Pi_{t-1} V_{t-1}}=\frac{\Pi_{t} M S I_{t} / p_{t}^{*}}{\Pi_{t-1} M S I_{t-1} / p_{t-1}^{*}}= \\
\frac{U_{t} M S I_{t}}{U_{t-1} M S I_{t-1}}=\frac{\sum_{n=1}^{N} \pi_{n, t} m_{n, t}}{\sum_{n=1}^{N} \pi_{n, t-1} m_{n, t-1}} .
\end{gathered}
$$

\section{CONSTRUCTING THE NEW MONETARY SERVICES INDEXES}

This section describes the specification and construction of selected components of the revised St. Louis MSI. The focus is largely, but not exclusively, on aspects of the MSI that differ substantively from our earlier work (Anderson, Jones, and Nesmith, 1997c). We caution readers that this section is necessarily detail oriented, but understanding the details, though sometimes tedious, is essential if the MSI are to be used intelligently in economic research and policymaking.

\section{Aggregation Levels, Components, and Segments}

The revised St. Louis MSI introduced in this article are monthly data beginning in January 1967; when this paper was written, the most recent available data were for May 2011. ${ }^{12}$ The indexes are published at five levels of aggregation: MSI-M1, MSI-M2, MSI-M2M, MSI-MZM, and MSI-ALL. MSI-M1 and MSI-M2 are defined over the financial assets included in the Federal Reserve Board's M1 and M2 monetary aggregates. MSI-ALL is defined over the broadest set of financial asset data currently available (to us), including the components of MSI-M2 plus institutional MMMFs. MSI-M2M and MSI-MZM are defined over zero-maturity assets-that is, financial assets immediately available for spending. More specifically, MSI-M2M is defined over the components of MSI-M2 except small-denomination time deposits, and MSI-MZM is defined over the components of MSI-M2M plus institutional MMMFs (equivalently, it includes all components of MSIALL except small-denomination time deposits).

Table 1 summarizes the components of the MSI. Readers should note that the number of components included in the MSI varies from month to month due to data availability. Examples of newly available data that increased the number of components include retail MMMFs (February 1973), institutional MMMFs (January 1974), other checkable deposits (OCDs) at com-

\footnotetext{
11 This follows from the fact that the expenditure shares add up to 1

${ }^{12}$ A qualification: Publication by the Board of Governors of figures regarding the deposit amounts involved in retail sweep programs lags by one month the publication of monetary data on the Board's H.6 statistical release. In constructing the MSI each month using the H.6 data, we carry forward the previous month's sweep program figures. These figures subsequently are replaced with published data as they become available.
} 


\section{Table 1}

\section{Components of the Monetary Services Indexes}

\begin{tabular}{|c|c|c|c|c|c|c|}
\hline Monetary asset & Sample period & M1 & M2M & MZM & M2 & ALL \\
\hline Currency & Jan. 1967-present & $\checkmark$ & $\checkmark$ & $\checkmark$ & $\checkmark$ & $\checkmark$ \\
\hline Travelers checks & Jan. 1967-present & $\checkmark$ & $\checkmark$ & $\checkmark$ & $\checkmark$ & $\checkmark$ \\
\hline Demand deposits & Jan. 1967-present & $\checkmark$ & $\checkmark$ & $\checkmark$ & $\checkmark$ & $\checkmark$ \\
\hline OCDs at commercial banks & Jan. 1986-present & $\checkmark$ & $\checkmark$ & $\checkmark$ & $\checkmark$ & $\checkmark$ \\
\hline OCDs at thrift institutions & Jan. 1986-present & $\checkmark$ & $\checkmark$ & $\checkmark$ & $\checkmark$ & $\checkmark$ \\
\hline Super NOW accounts at commercial banks & Jan. 1983-Dec. 1985 & $\checkmark$ & $\checkmark$ & $\checkmark$ & $\checkmark$ & $\checkmark$ \\
\hline Super NOW accounts at thrift institutions & Jan. 1983-Dec. 1985 & $\checkmark$ & $\checkmark$ & $\checkmark$ & $\checkmark$ & $\checkmark$ \\
\hline OCDs at commercial banks excluding Super NOW accounts & Jan. 1974-Dec. 1985 & $\checkmark$ & $\checkmark$ & $\checkmark$ & $\checkmark$ & $\checkmark$ \\
\hline OCDs at thrift institutions excluding Super NOW accounts & Jan. 1967-Dec. 1985 & $\checkmark$ & $\checkmark$ & $\checkmark$ & $\checkmark$ & $\checkmark$ \\
\hline Savings deposits at commercial banks & Sep. 1991-present & & $\checkmark$ & $\checkmark$ & $\checkmark$ & $\checkmark$ \\
\hline Savings deposits at thrift institutions & Sep. 1991-present & & $\checkmark$ & $\checkmark$ & $\checkmark$ & $\checkmark$ \\
\hline MMDAs at commercial banks & Dec. 1982-Aug. 1991 & & $\checkmark$ & $\checkmark$ & $\checkmark$ & $\checkmark$ \\
\hline MMDAs at thrift institutions & Dec. 1982-Aug. 1991 & & $\checkmark$ & $\checkmark$ & $\checkmark$ & $\checkmark$ \\
\hline Savings deposits at commercial banks excluding MMDAs & Jan. 1967-Aug. 1991 & & $\checkmark$ & $\checkmark$ & $\checkmark$ & $\checkmark$ \\
\hline Savings deposits at thrift institutions excluding MMDAs & Jan. 1967-Aug. 1991 & & $\checkmark$ & $\checkmark$ & $\checkmark$ & $\checkmark$ \\
\hline Retail money funds & Feb. 1973-present & & $\checkmark$ & $\checkmark$ & $\checkmark$ & $\checkmark$ \\
\hline Institutional money funds & Jan. 1974-present & & & $\checkmark$ & & $\checkmark$ \\
\hline Small-denomination time deposits at commercial banks & Jan. 1967-present & & & & $\checkmark$ & $\checkmark$ \\
\hline Small-denomination time deposits at thrift institutions & Jan. 1967-present & & & & $\checkmark$ & $\checkmark$ \\
\hline
\end{tabular}

mercial banks (January 1974), money market deposit accounts (MMDAs) (December 1982), and Super negotiable order of withdrawal (Super NOW) accounts (January 1983). ${ }^{13}$ The introduction of new assets is handled using a procedure suggested by Diewert (1980) (see Anderson, Jones, and Nesmith, 1997c, pp. 77-78, for details).

Because of data availability, each of the MSI is constructed in four segments: January 1967December 1985, December 1985-January 1987, January 1987-August 1991, and August 1991 onward. The published MSI are created by splicing these segments at their boundaries via rescaling. Because the MSI and their segments are

\footnotetext{
${ }^{13}$ Throughout this article, OCDs consists of NOW and automatic transfer service accounts at depository institutions, credit union share draft accounts, and demand deposits at thrift institutions. Demand deposits are deposits at commercial banks that are legally demandable from the bank without prior notice. MMDA deposits have limited third-party transfer features as specified by the GarnSt. Germain Act of 1982 and the Dodd-Frank Act of 2010.
}

index numbers, the information content of the MSI is unaffected by rescaling.

The first segment and the December 1985 splice are due to the fact that we have sufficient data to treat Super NOW accounts and other OCDs as separate components from the date they enter the MSI (January 1983) through December 1985; thereafter, the MSI include the totals of Super NOW accounts and other OCDs (at both commercial banks and thrift institutions) as single components. The second segment and the January 1987 splice are due to a change in the availability of interest rate data for MMMFs as discussed below. The third segment and the August 1991 splice are due to the fact that we have sufficient data to treat MMDAs and savings deposits as separate components from the time they enter the MSI (December 1982) through August 1991; thereafter, the MSI include the total of MMDAs and savings deposits (at both commercial banks and thrift institutions) as a single component. As 
discussed below, the source of the data used to construct own rates for the deposit components of the MSI also differs before and after August 1991.

\section{Retail Sweep Adjustment}

Retail sweep programs at depository institutions began in January 1994. The Federal Reserve's Board of Governors described the purpose and effects of these programs in its annual report for 1999 (p. 59):

Deposits in M1 declined further in 1998, reflecting the continued introduction of retail "sweep" programs. Growth of M1 deposits has been depressed for a number of years by these programs, which shift—or "sweep"balances from household transactions accounts, which are subject to reserve requirements, into savings accounts, which are not. Because the funds are shifted back to transactions accounts when needed, depositors' access to their funds is not affected by these programs. However, banks benefit from the reduction in holdings of required reserves, which do not pay interest.

In the Board's H.6 statistical release, funds that have been swept from transaction deposits to savings deposits (specifically, to MMDAs) are included in published savings deposit figures rather than in transaction deposit figures. Hence, published figures for demand deposits and OCDs are too small relative to the deposit amounts that consumers and firms perceive themselves as holding at depository financial institutions, and published figures for savings deposits are too high. (Note that the published sum of transaction deposits plus savings deposits, and hence the Federal Reserve's M2 monetary aggregate, is unaffected by retail deposit sweep activity.) Precise data on the amount of deposits affected by retail deposit sweeping are not available because banks are not required to report to the Federal Reserve the amounts of deposits affected by retail sweep programs. Nevertheless, Federal Reserve Board staff estimate the amounts each month, and their estimates are available publicly on the St. Louis Fed's website. ${ }^{14}$ Figure 1 plots demand deposits, OCDs, and their sum since 1994 both as reported on the H.6 statistical release and after adjustment for sweep effects. According to these estimates, since 2001 no less than 41 percent of total transaction deposits has been swept into savings deposits under retail sweep programs; between early 2005 and late 2008, more than 50 percent of such deposits was swept. If the estimated amounts of funds swept since 2001 were added to the Federal Reserve's M1 monetary aggregate, its level would increase by 27 percent to 36 percent. (Note: Figure 1 incorporates an estimated separation of swept amounts between demand deposits and OCDs; this allocation is based on unpublished data that are not publicly available.)

Due to insufficient data, Anderson, Jones, and Nesmith (1997c) did not consider the effects of retail sweeping on the MSI. In this revision, the MSI are constructed from data adjusted for the effects of retail sweeping (see Jones, Dutkowsky, and Elger, 2005). ${ }^{15}$ Specifically, estimated swept amounts are added to demand deposits and OCDs and subtracted from savings deposits. The adjustment significantly affects MSI-M1 because savings deposits are not included in that index, while the effect is much smaller on the broader indexes. ${ }^{16}$ Figure 2 plots MSI-M1 against a comparable index constructed over components not adjusted for retail sweeping; failing to adjust for the effects of retail sweeps causes significant understatement of MSI-M1. ${ }^{17}$

\footnotetext{
${ }^{14}$ See http://research.stlouisfed.org/aggreg/swdata.html. These figures are produced by the staff of the Federal Reserve Board. The precise method of estimation is not made public. For further discussion of retail sweeping, see Anderson (1995), Anderson and Rasche (2001), Dutkowsky and Cynamon (2003), Duca and VanHoose (2004), Jones, Dutkowsky, and Elger (2005), Dutkowsky, Cynamon, and Jones (2006), Elger, Jones, and Nilsson (2006), and Jones et al. (2008).

15 Jones, Dutkowsky, and Elger (2005) adjust the MSI components for the effects of both retail and commercial sweeps. We do not consider the effects of commercial sweeping in this paper. Elger, Jones, and Nilsson (2006) analyze a Divisia M1 series constructed with data adjusted for the effects of retail sweeping.

16 This, of course, also is true for summation aggregates such as those published on the Federal Reserve Board's H.6 statistical release. The Federal Reserve's M2 aggregate is unaffected by retail sweeping, while the level of the M1 aggregate is significantly reduced.

17 The indexes plotted in the figure are constructed using our preferred benchmark rate. Measurement of the benchmark rate is addressed in the next section.
} 


\section{Figure 1}

\section{Retail Sweeping of Transaction Deposits (1994-2011)}
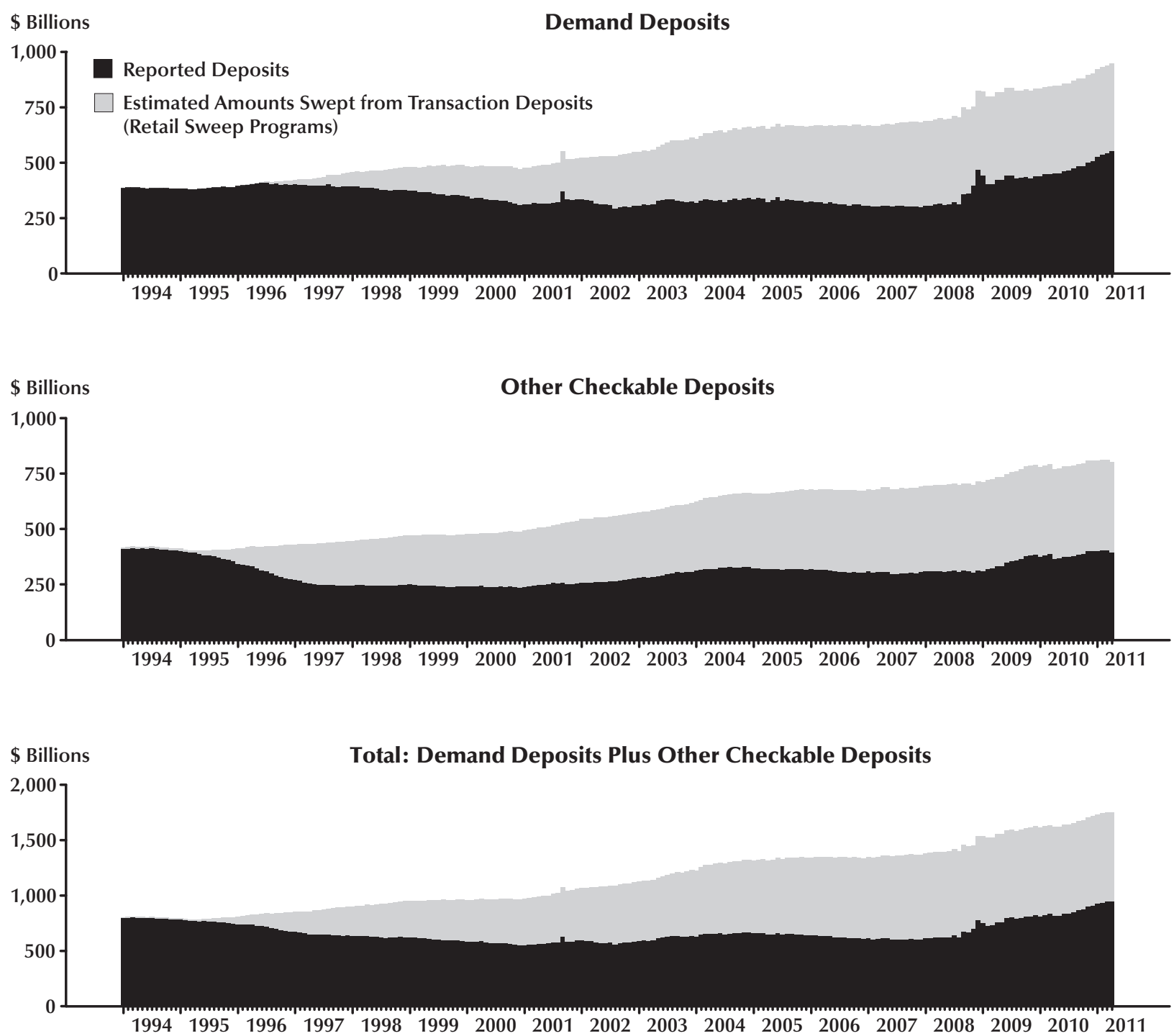

\section{Benchmark Rates}

The theory of monetary aggregation assumes that there exists a benchmark asset that furnishes no monetary services-that is, an asset that is used only to transfer wealth from period to period. It is assumed that the benchmark asset provides no "standby" or precautionary liquidity because it is not convertible into medium of exchange during the planning period at less than a confiscatory transaction cost. While the conceptual definition of the benchmark asset is straightforward, measuring that concept is not at all so. As noted by Fisher, Hudson, and Pradhan (1993, p. 243) and Barnett (2003, p. 50), the benchmark asset cannot be an asset that is easily traded on a secondary market. Today, however, almost all financial assets may be used as collateral in repurchase transac- 


\section{Figure 2}

\section{Effect of Retail Sweep Adjustments on MSI-M1 (1994-2011)}

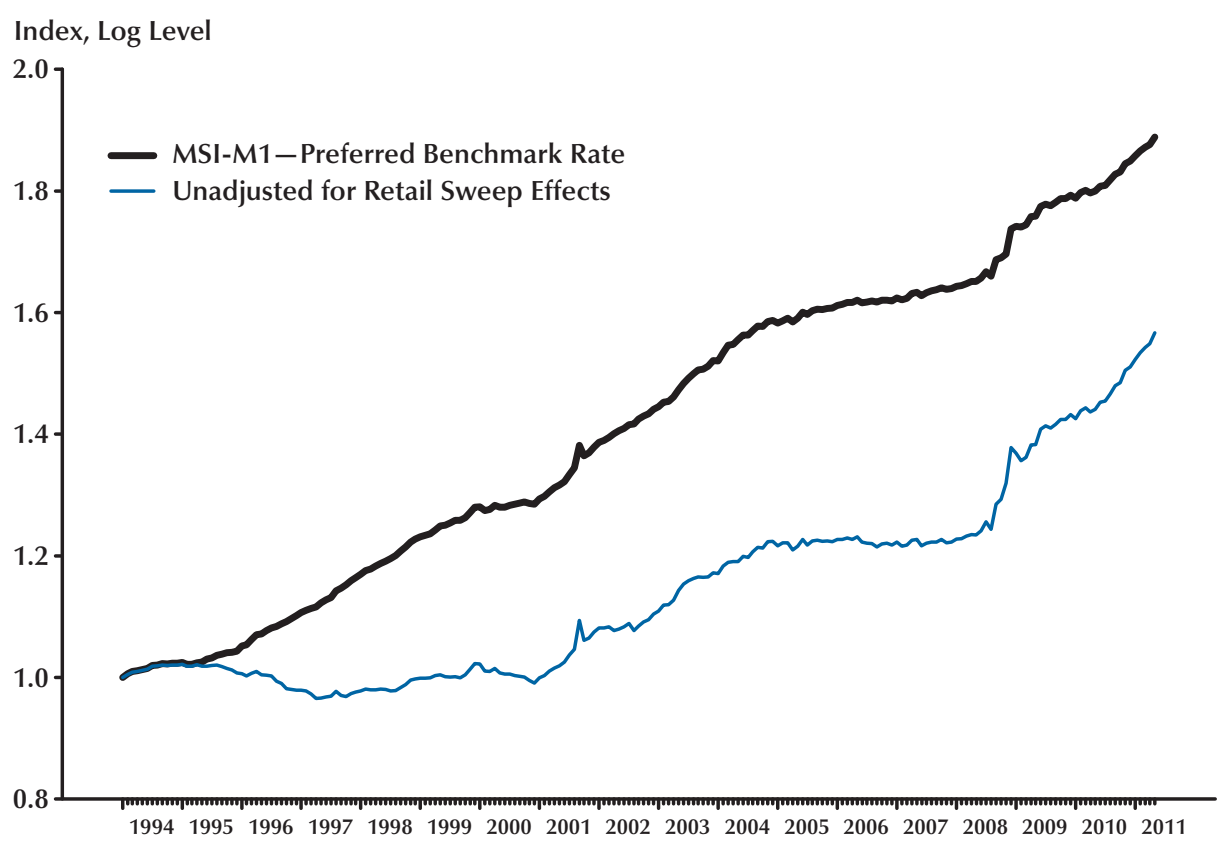

NOTE: Both indexes are scaled so that the log level is 1 in January 1994.

tions, thereby allowing conversion of the asset into medium of exchange without its sale. How, then, is the benchmark rate to be measured?

Fisher, Hudson, and Pradhan (1993) developed U.K. Divisia money measures for the Bank of England. As described by Hancock (2005, pp. 40-41), before a set of recent changes to those measures the benchmark rate was the 3-month rate on local government bills plus a premium of 200 basis points. Without the added premium, the benchmark rate would sometimes be below the own rates of some components. ${ }^{18}$ Following Fisher, Hudson, and Pradhan (1993), Jones et al. (2008) constructed user costs for the components of MSI-M2 using the 6-month Treasury bill rate plus 200 basis points as the benchmark rate for the period from 1987 to $2004 .^{19}$

Following Barnett and Spindt (1982), the Divisia monetary aggregates produced by the Board of Governors and subsequently by the St. Louis Fed have all taken the benchmark rate to be the maximum of the Baa corporate bond yield and the set of interest rates used to construct the component user costs. However, this approach clearly is subject to mismeasurement. In any stochastic model with forward-looking agents, the anticipated flows of income and consumption relative to expected holding-period yields (including transaction costs) determine, at least in part, agents' portfolio choices (including the quantities of monetary assets) and hence the purchased quantities of monetary services. Stracca (2004, p. 313) emphasizes the econometrician's inability to measure these expected holding period yields for long-maturity assets:

Theoretically, the benchmark asset should be capital-certain....and at the same time provide

\footnotetext{
${ }^{18}$ From a measurement error perspective, if the measure of the benchmark rate generates negative user costs, then the measurement error in that measure is relatively high.

${ }^{19}$ Hancock (2005, p. 42) notes that a Treasury bill rate could be used as a proxy for the rate on local government bills. Bissoondeeal et al. (2010) construct a U.K. index following this suggestion.
} 
no liquidity services altogether. Long-term bond yields are often used as benchmark rates, but this approach is somewhat problematic...In fact, if agents have a relatively short time horizon in their portfolio allocation, what matters as an opportunity cost is not the long-term yield to maturity of the bond portfolio, but rather its expected short-term rate of return. However, this expected return cannot be observed directly, and must be proxied in some way.

Barnett (2003, p. 50) argues against including a bond yield in the calculation, preferring instead to "add to the upper envelope [over the component yield-curve-adjusted rates of return] a rate structure premium representing the premium for giving up the liquidity of the assets within the envelope."20

Stracca (2004) constructed a euro-zone Divisia M3 monetary aggregate along these lines. He used a short-term market interest rate to represent the own rate for the marketable securities in M3 and that rate exceeded the own rates of the other components of M3. ${ }^{21}$ As he explains (p. 317), "We assume that the marketable instruments included in [euro] M3 provide some limited liquidity service and that they are risk free. Under these assumptions, the rate of return on a risk-free short-term financial asset providing no transaction services should be given by a short-term market interest rate plus a 'liquidity services premium.", In practice, he set the liquidity premium equal to 60 basis points, which was the average spread between the short-term market rate and a 10-year government bond rate. He found that (i) "similar values of the premium lead to very similar patterns of the Divisia monetary aggregate" and (ii) the "annual growth rate of the Divisia index computed in this manner is very close to-indeed almost indistinguishable from-that of a Divisia index computed taking the 10-year market interest rate as the benchmark rate."

We find Stracca's (2004) reasoning compelling-namely, that the benchmark rate should exceed short-term money market interest rates. The benchmark rate also must generate positive

\footnotetext{
${ }^{20}$ For another perspective on the benchmark rate, see Drake and Mills (2005, pp. 153-54).

${ }^{21}$ See Figure 1 (p. 315) of his paper.
}

user costs for components of MSI-ALL in order to calculate that index. As such, we begin by taking the maximum in each period over a set of rates that includes all own rates of the components of our broadest index (MSI-ALL), as well as the short-term yields on selected money market instruments, such as Treasury bills, commercial paper, eurodollar deposits, and negotiable certificates of deposit. ${ }^{22}$ We include yields on instruments with maturities of up to six months to be consistent with our measurement of the own rate on small-denomination time deposits (discussed below). Following the literature, we refer to this maximum rate as the upper envelope. The upper envelope usually, though not always, equals one of the short-term money market yields. Following our previous discussion, we construct a benchmark rate by adding a liquidity services premium to this upper envelope. Doing so, however, requires that we determine a reasonable value for the liquidity premium. We construct MSI using a benchmark rate equal to the upper envelope plus a constant (that is, not time-varying) liquidity premium of 100 basis points, which we refer to as our "preferred" benchmark rate.

As discussed previously, Stracca (2004) selected a somewhat lower liquidity premium than we do ( 60 basis points). Another point of comparison is Jones et al. (2008), who defined the benchmark rate as the 6-month Treasury bill rate plus 200 basis points. Here, a benchmark rate so constructed exceeds our upper envelope throughout November 1982 to August 2008 by an average of 144 basis points, suggesting a higher liquidity premium of 144 basis points might be reasonable. ${ }^{23}$ On the other hand, adding just 152 basis points (rather than 200 basis points) to the 6-month Treasury bill rate is sufficient to produce a benchmark rate that exceeds the upper envelope in all but two months over this period. In

\footnotetext{
${ }^{22}$ Previously, these rates had been used to construct the MSI-L aggregate in Anderson, Jones, and Nesmith (1997c).

${ }^{23}$ The 6-month Treasury bill rate itself is always below the upper envelope during this period. A considerably larger premium would need to be added to the 6-month Treasury bill rate for the resulting benchmark rate to exceed the upper envelope during the height of the financial crisis. This is also the case in some earlier periods, including 1980-81.
} 
Figure 3

\section{Effect of Benchmark Rate on Year-over-Year Percentage Growth of MSI-ALL (1983-2011)}

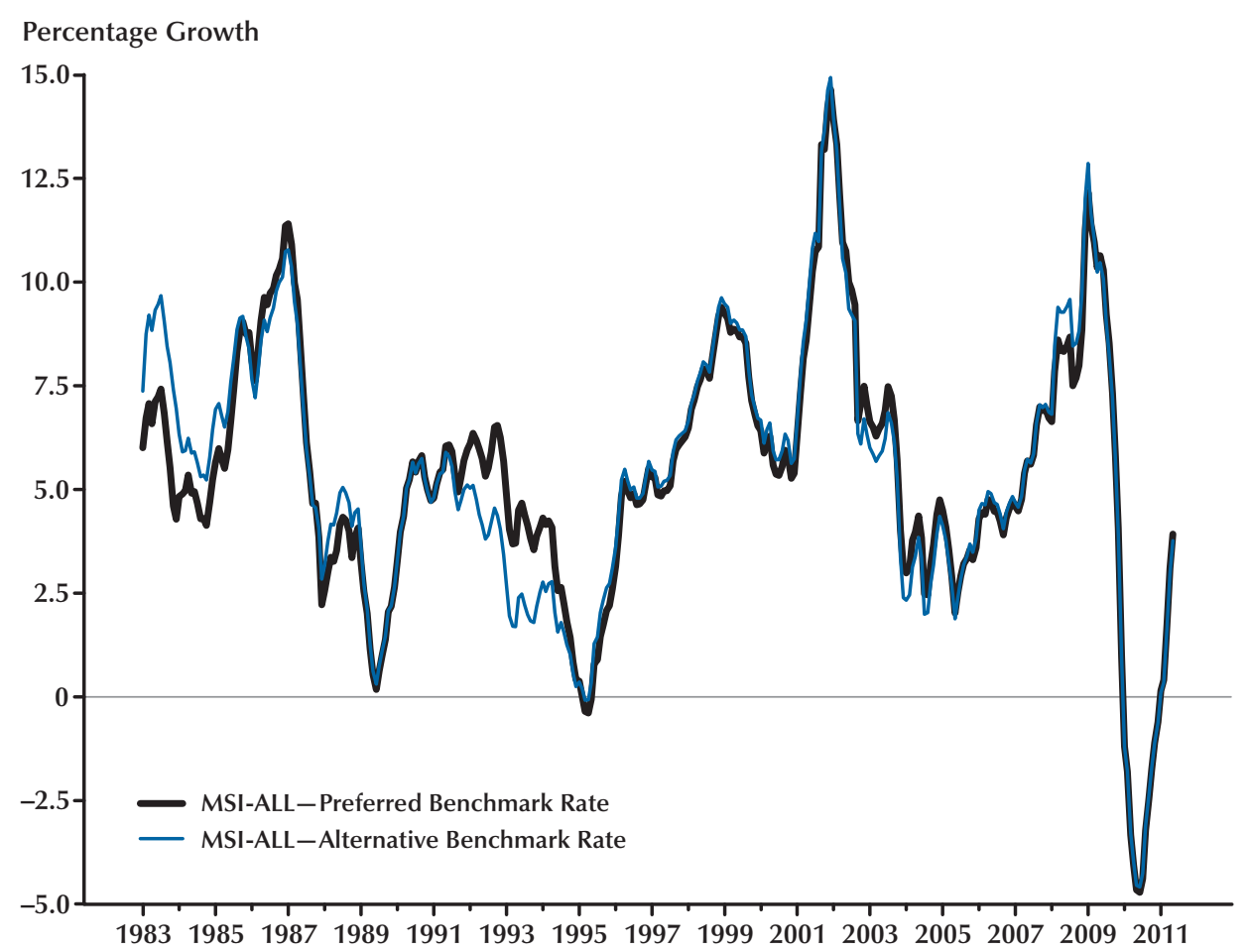

our judgment, adding 100 basis points to the upper envelope produces a plausible benchmark rate. Yet because this liquidity premium, essentially, is judgmental, it is important to assess the sensitivity of the resulting MSI to this choice. To measure the sensitivity of the MSI to the liquidity premium, we calculated month-to-month and year-over-year growth rates of pairs of MSI incorporating liquidity premiums of 60 and 144 basis points (rather than 100, which is used for our preferred benchmark rate) for each of the five levels of aggregation. The correlations of the growth rates for all pairs, at all five levels of aggregation, exceeded 0.98, confirming Stracca's conclusion that the behavior of monetary index numbers, including our MSI, is not highly dependent on the precise size of the liquidity premium.

We also calculate MSI using an "alternative" benchmark rate that incorporates the Baa bond yield. The alternative benchmark rate is calculated by setting the benchmark rate equal to the larger of (i) the Baa bond yield and (ii) our preferred benchmark rate, such that the alternative benchmark rate equals the Baa bond yield only in months when the bond yield exceeds the upper envelope by more than 100 basis points. Note that this calculation differs from the practice in many earlier Divisia analyses in which the Baa bond yield was included in the set of rates used to select the upper envelope and no liquidity premium was added to the upper envelope. Our rationale is that if the sum of the upper envelope plus a 100-basis-point liquidity premium (our preferred benchmark) is a sensible measure of the benchmark rate, then the Baa bond yield should be used as the benchmark rate only when it exceeds the upper envelope by more than 100 basis points. In the earlier years of our data (1967-81), our preferred benchmark exceeds the Baa bond yield 
approximately 58 percent of the time-that is, the preferred and alternative benchmark rates are the same more often than not. In contrast, during the later period (1982-2011), the Baa bond yield exceeds our preferred benchmark rate approximately 95 percent of the time; the exceptions are in 1989 and 2006-07.

Over the 1983-2011 period, the correlation between the growth rates of indexes calculated using the two benchmark rates (month-to-month or year-over-year) exceeds 0.93 for all five aggregation levels. Figure 3 compares year-over-year growth rates for MSI-ALL using the two benchmark rates. The comparable figure for MSI-M2 (not shown) is similar to the one for MSI-ALL. For MSI-M2M and MSI-MZM, year-over-year growth rates using the two benchmark rates differ significantly in 1983 but much less so subsequently.

\section{Own Rates of Return}

The MSI require estimates of the user costs of each component, which are derived from the spread between the benchmark rate of return and the component's own rate of return. Measurement issues with respect to the benchmark rate were discussed above. Here, we discuss issues related to own rates of return on deposits at financial institutions. With respect to measurement error, Goldfeld and Sichel (1990, p. 316) write: “A first issue concerns the own rate where there are obvious measurement difficulties created via the payment of implicit interest by the provision of services and the existence of explicit service charges. The lack of data makes it hard to evaluate the seriousness of these difficulties." Therefore, our assumptions are listed below:

Currency and travelers checks. We assume a zero own rate.

Demand deposits. We assume a zero own rate, although some demand deposits earn an implicit rate of return. As discussed by Donald Kohn (in testimony to the Committee on Banking, Housing, and Urban Affairs, U.S. Senate, June 22, 2004):

The prohibition of interest on demand deposits distorts the pricing of transaction deposits and associated bank services. In order to compete for the liquid assets of businesses, banks have been compelled to set up complicated proce- dures to pay implicit interest on compensating balance accounts. Banks also spend resourcesand charge fees-for sweeping the excess demand deposits of businesses into money market investments on a nightly basis.

The prohibition of interest on demand deposits also distorts the pricing of other bank products. Many demand deposits are not compensating balances, and because banks cannot pay explicit interest, they often try to attract these deposits by pricing other bank services below their actual cost.

Interest on demand deposits would clearly benefit small businesses, which currently earn no interest on their checking accounts. But larger firms would also benefit as direct interest payments replaced more costly sweep and compensating balance arrangements.

Barnett and Spindt (1982), Farr and Johnson (1985), and Thornton and Yue (1992) separated household and business demand deposits when constructing Divisia monetary aggregates. Household deposits were assigned an own rate of zero, but business demand deposits were assumed to earn an implicit rate of return equal to a shortterm commercial paper rate net of the statutory required reserve ratio consistent with firms holding balances to compensate their banks for services used (see Mahoney, 1988, pp. 198-99 for further discussion). The data used in these studies to separate demand deposits into household and business components are not available after June 1990 (see Thornton and Yue, 1992, p. 46). Consequently, Anderson, Jones, and Nesmith (1997c) adopted an alternative procedure, assuming that the implicit rate of return on demand deposits was a fraction of the fully competitive return and applying that own rate to total demand deposits.

In the revised MSI reported in this article, we set the own rate of return on demand deposits to zero (rather than impute a rate of return) due to the lack of data concerning the relative ownership of demand deposits by households and businesses. ${ }^{24}$

\footnotetext{
${ }^{24}$ In addition, commercial sweeping of [business] demand deposits into Treasury bills, institutional MMMFs, eurodollar accounts, and similar liquid money market instruments increased significantly during the 1990s (see Jones, Dutkowsky, and Elger, 2005). (Recall that retail deposit sweeping consists of reclassifying checkable Continued on next page
} 


\section{Figure 4}

\section{Effect of Implicit Returns on Year-over-Year Percentage Growth of MSI-M1 (April 1972-June 1990)}

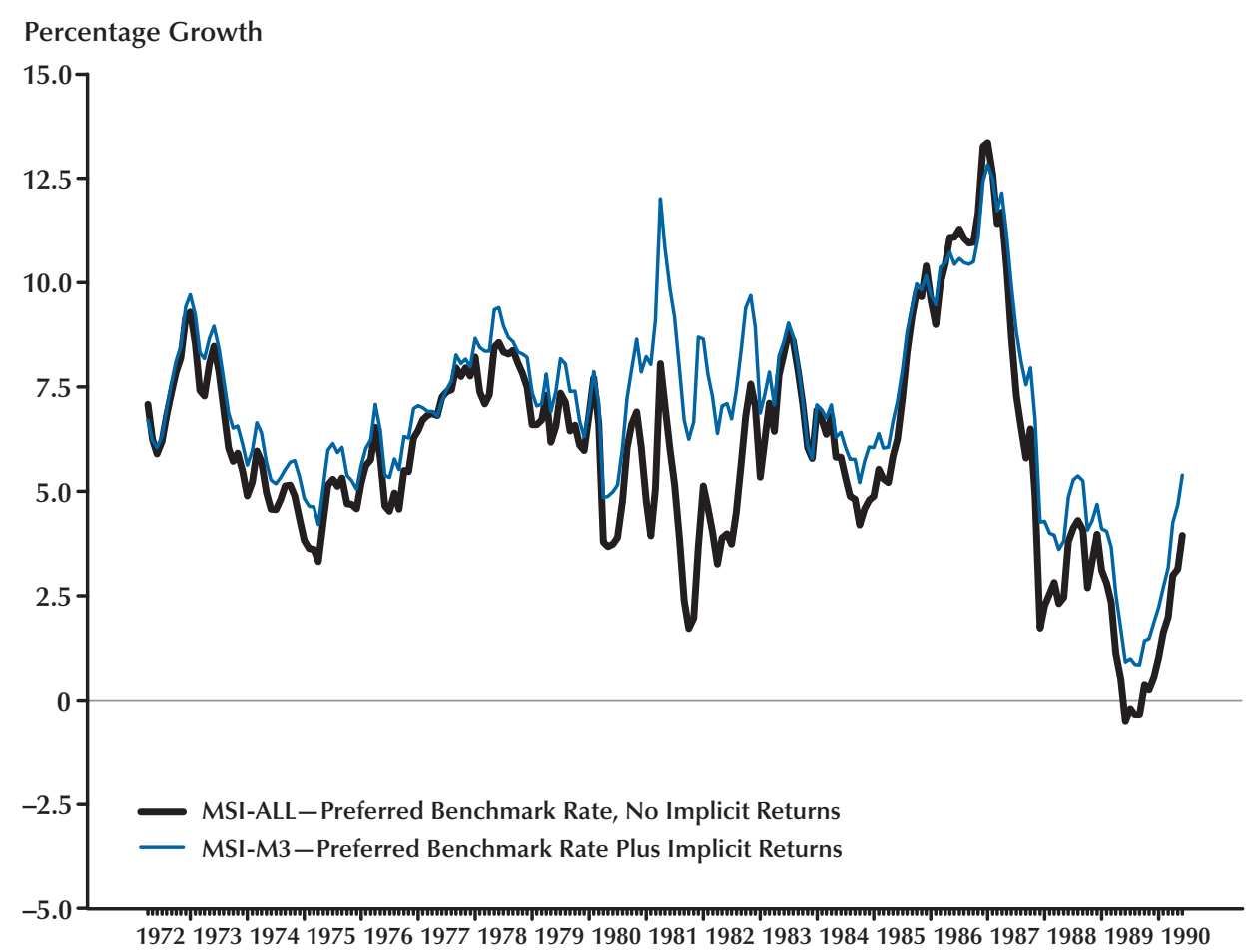

To assess the implications of the zero own rate, we created pairs of MSI for April 1971-June 1990 at all five levels of aggregation, in which we assigned a zero own rate to demand deposits in one MSI and, in the other assigned business demand deposits an own rate equal to the onemonth commercial paper rate (adjusted for the statutory reserve requirement tax on banks) and household demand deposits an own rate of zero, following closely Farr and Johnson (1985). ${ }^{25}$ (All

deposits as MMDA deposits for the purpose of calculating statutorily required reserves; these deposits do not leave the bank.) To the extent that demand deposits are swept into institutional MMMFs, they will be included in the MSI that contain those MMMFsspecifically, MSI-MZM and MSI-ALL. To the extent that the deposits are swept into money market instruments omitted from the MSI and that the owners of these swept funds continue to regard them as money, the MSI will understate the flow of monetary services received and consumed by the owners of these deposits. Of course, summation aggregates such as those reported on the Federal Reserve Board's H.6 statistical release will be understated for the same reason (see Cynamon, Dutkowsky, and Jones, 2006). pairs used our preferred benchmark rate.) The correlation of the growth rates (month-to-month and year-over-year) of the pairs exceeds 0.98 except at the M1 level of aggregation, where the correlation was 0.93 for month-to-month growth rates and 0.91 for year-over-year growth rates. Figures 4 and 5 show year-over-year growth rates for the pairs of MSI-M1 and MSI-ALL, respectively.

Money market mutual funds. The own rates of return for MMMFs are unpublished data obtained from the Federal Reserve Board. A single rate is available beginning in June 1974, while separate rates for retail and institutional MMMFs are available beginning in January 1987. We use the separate rates when they are available and, as mentioned above, splice the MSI in January

\footnotetext{
25 The data used to construct the household and business demand deposit series are available back to June 1970 but the data for the one-month commercial paper rate are available only starting in April 1971.
} 


\section{Figure 5}

Effect of Implicit Returns on Year-over-Year Percentage Growth of MSI-ALL (April 1972-June 1990)

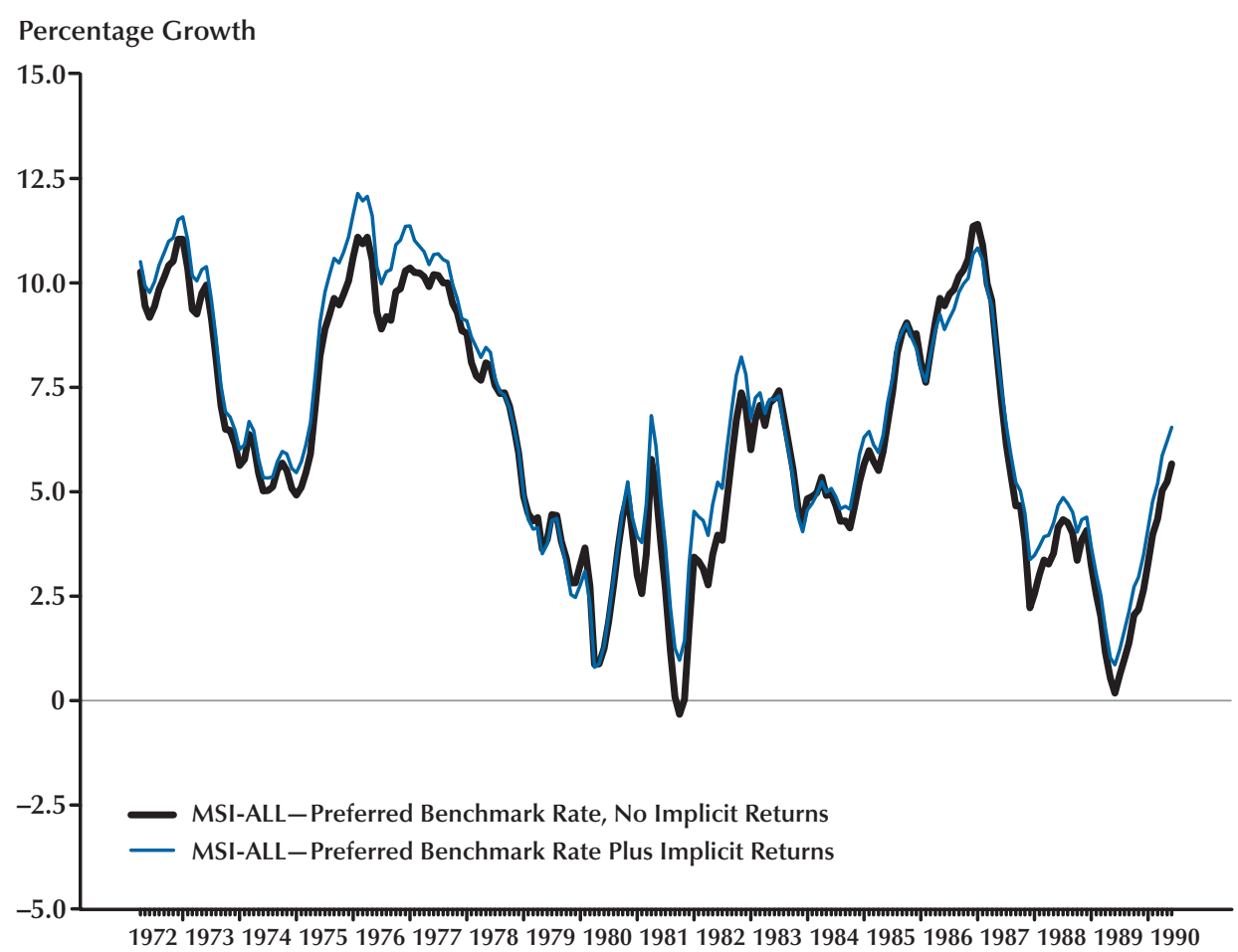

1987. ${ }^{26}$ Specifically, in the first two segments covering the periods up to January 1987, we apply the single rate to both retail and institutional MMMFs, whereas in the latter two segments covering the periods from January 1987 onward, we use separate rates.

Other bank and thrift deposits. Table 2 details the data used to measure own rates of return for the deposit components of the MSI up to August 1991. Available data include monthly figures for deposit own rates published between 1983 and 1997 by the Federal Reserve Board in a supplementary table (Monthly Survey of Selected Deposits [FR2042]) to the H.6 statistical release. ${ }^{27}$ In addition, data beginning January 1987 have

\footnotetext{
${ }^{26}$ Quantity figures for retail MMMFs begin in February 1973, so we must construct a proxy for the rate between February 1973 and May 1974. We do this via a regression against the overnight federal funds rate as in Anderson, Jones, and Nesmith (1997c, p. 66).
}

been purchased by the Federal Reserve from the Bank Rate Monitor Corporation. In our calculations, we choose to use the Federal Reserve's figures (rather than the Bank Rate Monitor data) through August 1991 because this allows us to treat MMDAs as a separate component for the longest possible time period. Although the Federal Reserve Board's figures are available through 1996, for continuity we choose to use the Bank Rate Monitor data in the final segment of the indexes (i.e., beginning in August 1991). A series of calculations confirmed that the choice has very little effect on the indexes. For small-

\footnotetext{
${ }^{27}$ These data are available from the Federal Reserve Board beginning in October 1983 but the published tables contain data going back to April 1983 for Super NOWs and to May 1983 for MMDAs. We used those additional observations to construct own rates after rescaling them to coincide with the data obtained from the Federal Reserve Board in October 1983. The first available observations for Super NOWs and MMDAs are applied for the first few months those assets are included in the MSI.
} 


\section{Table 2}

\section{OWN Rates for Deposit Components before August 1991}

\author{
Monetary asset \\ Currency, travelers checks, and demand \\ deposits \\ OCDs at commercial banks \\ OCDs at thrift institutions \\ OCDs at commercial banks excluding Super \\ NOW accounts
}

OCDs at thrift institutions excluding Super NOW accounts

Super NOW accounts at commercial banks

Super NOW accounts at thrift institutions

Savings deposits at commercial banks excluding MMDAs

Savings deposits at thrift institutions excluding MMDAs

MMDAs at commercial banks

MMDAs at thrift institutions

\section{Sample period}

Jan. 1967-present

Jan. 1986-Aug. 1991

Jan. 1986-Aug. 1991

Jan. 1974-Dec. 1980

Jan. 1981-Jan. 1982

Feb. 1982-Dec. 1985

Jan. 1967-Dec. 1973

Jan. 1974-Dec. 1985

Oct. 1983-Dec. 1985

Oct. 1983-Dec. 1985

Jan. 1967-Jan. 1982

Feb. 1982-Dec. 1983

Jan. 1984-March 1986

April 1986-Aug. 1991

Jan. 1967-Dec. 1969

Jan. 1970-June 1973

July 1973-Jan. 1982

Feb. 1982-March 1986

April 1986-Aug. 1991

Oct. 1983-Aug. 1991

Oct. 1983-Aug. 1991

\section{Own rate}

Zero

Average rate paid, NOW accounts, commercial banks*

Average rate paid, NOW accounts, savings banks*

Minimum $\left(5.0 \%{ }^{\dagger}\right.$, average of most common rate, savings deposits ${ }^{\ddagger}$ )

Minimum $\left(5.25 \%^{\dagger}\right.$, average of most common rate, savings deposits ${ }^{\ddagger}$ )

$5.25 \%+$

Zero

Same as commercial bank rate

Average rate paid, Super NOW accounts, commercial banks*

Average rate paid, Super NOW accounts, savings banks*

Average of most common rate, savings deposits ${ }^{\ddagger}$

$5.25 \%{ }^{+}$

$5.5 \%{ }^{+}$

Average rate paid, savings accounts, commercial banks*

Commercial bank rate plus 75 basis points ${ }^{\S}$

Commercial bank rate plus 50 basis points

Commercial bank rate plus 25 basis points

$5.5 \%{ }^{+}$

Average rate paid, savings accounts, savings banks*

Average rates paid, money market deposit accounts, commercial banks* Average rates paid, money market deposit accounts, savings banks* 


\section{Table 2, cont'd}

\section{OWN Rates for Deposit Components before August 1991}

\section{Monetary asset \\ Sample period}

Small-denomination time deposits at commercial banks
Jan. 1967-March 1970

April 1970-June 1976

July 1976-May 1978

June 1978-Sep. 1983

Oct. 1983-Aug. 1991

Small-denomination time deposits at thrift institutions

Jan. 1967-May 1978

\section{Own rate}

Average of most common rate, consumer-type time deposits ${ }^{\ddagger}$

Average of most common rate, time deposits in denominations of less than $\$ 100,000$, maturing in less than 1 year $^{\ddagger}$

Average of most common rate, time deposits in denominations of less than $\$ 100,000$, other than domestic governmental units, maturing in 90 up to 180 days $^{\ddagger}$

Variable ceiling rate, money market time deposits, 6 months, commercial banks ${ }^{\#}$

Average rate paid, interest-bearing deposits with balances of less than $\$ 100,000$ with original maturities of 92 to 182 days, commercial banks* Commercial bank rate plus 25 basis points**,+t

June 1978-Sep. 1983 Variable ceiling rate, money market time deposits, 6 months, thrifts ${ }^{\#}$

Oct. 1983-Aug. 1991
Average rate paid, interest-bearing deposits with balances of less than $\$ 100,000$ with original maturities of 92 to 182 days, savings banks*

NOTE: *The data are obtained from the Federal Reserve. ${ }^{\dagger}$ See Table 8, Annual Statistical Digest (http://fraser.stlouisfed.org/publications/ astatdig/), various issues. ${ }^{\ddagger}$ Quarterly estimates are obtained from the Federal Reserve Bulletin (http://fraser.stlouisfed.org/publications/ $\mathrm{FRB} /$ ), various issues. Interpolated to obtain monthly values as described in text. \$The Board of Governors established a maximum rate of 4 percent on savings deposits over this period; see Table 12.4A, Banking and Monetary Statistics 1941-1970 (http://fraser.stlouisfed.org/ publications/bms2/). Over the same period, Table S.4.12, Federal Home Loan Bank Board Journal (January 1974, p. 51) reports that the maximum rate payable on regular savings accounts was 4.75 percent for savings and loan associations. We therefore set the own rate on savings deposits at thrift institutions as the commercial bank rate plus 75 basis points. IThe added basis points equal the spread between the maximum rates payable on savings deposits at savings and loan associations and mutual savings banks versus those at commercial banks from Table 8, Annual Statistical Digest, various issues. \#Variable ceiling rates were obtained from the Federal Reserve Bulletin, various issues. ${ }^{* *}$ From January 1967 to December 1969, the Board of Governors established a maximum rate of 5 percent on single-maturity time deposits of less than $\$ 100,000,30$ days to 1 year; see Table 12.4, Banking and Monetary Statistics 1941-1970. Over the same period, Table S.4.12, Federal Home Loan Bank Board Journal (January 1974, p. 51) reports that the maximum rate payable on accounts with maturities of 6 months to 1 year was 5.25 percent for savings and loan associations. We therefore set the own rate on small-denomination time deposits at thrift institutions as the commercial bank rate plus 25 basis points. ${ }^{\text {tt}}$ From January 1970 to June 1973 , the added basis points equal the spread between the maximum rates payable on single-maturity time deposits of less than $\$ 100,000,30$ days to 1 year, at savings and loan associations and mutual savings banks versus those at commercial banks; from Table 8, Annual Statistical Digest, various issues. From July 1973 to May 1978, the added basis points equal the spread between the maximum rates payable on time accounts, 90 days to 1 year, at savings and loan associations and mutual savings banks versus those at commercial banks; from Table 8, Annual Statistical Digest, various issues. 
denomination time deposits, the own rate is based on a 6-month maturity.

A key issue in constructing the MSI is that deposits were subject to interest rate ceilings under Regulation Q; our discussion here draws on Gilbert (1986). Generally speaking, Anderson, Jones, and Nesmith (1997c) assumed that the interest rate ceilings were binding and used them to form own rates for the components of the MSI going back to 1960. According to Gilbert (1986, p. 26), however, this was typically not the case before 1966:

From the mid-1930s to the mid-1960s, the ceiling rates on time and savings deposits generally were above market interest rates and above the average interest rates paid on time and savings deposits by member banks. In 1957 and 1962, when market interest rates rose near or above the ceiling rates on savings deposits, these ceilings were raised...Thus, for the first 30 or so years of their existence, ceiling interest rates on time and savings deposits were above interest rates on Treasury securities in all but a few months, and average interest rates paid by member banks on all time and savings deposits were below the lowest ceiling rate in effect, the rate on savings deposits.

Moreover, as noted by Gilbert, thrift institutions were subject to interest rate ceilings only beginning in 1966 (see Ruebling, 1970).

Quarterly figures for interest rates paid by commercial banks on various types of time and savings deposits are available from January 1967 to January 1982; these figures were based on surveys by the Federal Reserve Board and the Federal Deposit Insurance Corporation (FDIC) (see Lefever, 1979). In the revised MSI presented in this article, monthly own rates for commercial bank deposits are estimated from these published quarterly figures. The start date for the MSI has been changed to January 1967 (previously, it was January 1960), reflecting the availability of the quarterly data and the fact that thrift rates were not subject to ceilings until 1966. Through January 1982, monthly own rates on savings deposits at commercial banks (excluding MMDAs) are obtained by interpolation from the published quarterly figures. ${ }^{28}$ Due to a lack of data, the own rate on savings deposits at thrift institutions is set equal to the own rate at commercial banks plus the difference between the corresponding ceiling rates. From February 1982 until March 1986, the own rates are set at the corresponding ceilings. The Federal Reserve's monthly figures are available beginning in April 1986.

For small-denomination time deposits at commercial banks, the availability of quarterly figures changes through time. For January 1967March 1970, we use the published rate for "consumer-type" time deposits. For April 1970June 1976, we use the rate on deposits maturing in less than a year. ${ }^{29}$ For July 1976-May 1978 , we use the rate on deposits maturing in 90 to 180 days. Similar to savings deposits, monthly estimates of own rates on small-denomination time deposits at commercial banks are interpolated from the quarterly figures. For January 1967-May 1978, we set the own rate for smalldenomination time deposits at thrift institutions equal to the own rate on deposits at commercial banks plus the difference between the corresponding interest rate ceilings.

Beginning in June 1978, commercial banks and thrift institutions were permitted to offer 6month money market time deposits with ceiling rates tied to average auction yields on 6 -month Treasury bills. Survey evidence suggests that rates paid were close to the ceilings. Consequently, we set the own rate on small-denomination time deposits at commercial banks and at thrift institutions for June 1978-September 1983 equal to the ceiling rates on 6-month money market time deposits. The Federal Reserve Board's monthly figures are available beginning in October 1983.

Due to lack of data, the own rate on OCDs at commercial banks (excluding Super NOWs) is assumed to be the smaller of the own rate on savings deposits at commercial banks and the ceiling

\footnotetext{
${ }^{28}$ We interpolate using cubic splines over periods when the ceiling rate is unchanged. When the ceiling rate changes, the last available estimate is used until the new ceiling is in effect. If the quarterly estimate is unchanged between two or more survey dates, we use that value for the intervening months.

${ }^{29}$ Note that the January 1970 figure for consumer-type time deposits reflects an increase in certain ceiling rates, but ceilings did not increase for deposits with maturities of less than one year. Thus, we actually use the October 1969 value until March 1970. The April 1976 estimate for deposits with maturities of less than one year is used for May and June 1976.
} 


\section{Table 3}

Correlations: Growth Rates of MSI and Sum Aggregates*

\begin{tabular}{|c|c|c|c|c|c|}
\hline & M1 & M2M & M2 & MZM & ALL \\
\hline \multicolumn{6}{|c|}{ Correlations between MSI } \\
\hline $\mathrm{M} 2 \mathrm{M}$ & 0.75 & & & & \\
\hline M2 & 0.75 & 0.90 & & & \\
\hline MZM & 0.69 & 0.95 & 0.89 & & \\
\hline ALL & 0.66 & 0.82 & 0.94 & 0.91 & \\
\hline M3 & 0.69 & 0.82 & 0.95 & 0.85 & 0.97 \\
\hline \multicolumn{6}{|c|}{ Correlations between sum aggregates } \\
\hline & M1 & M2M & M2 & MZM & ALL \\
\hline $\mathrm{M} 2 \mathrm{M}$ & 0.53 & & & & \\
\hline M2 & 0.49 & 0.68 & & & \\
\hline MZM & 0.46 & 0.95 & 0.67 & & \\
\hline ALL & 0.36 & 0.58 & 0.88 & 0.72 & \\
\hline M3 & 0.25 & 0.32 & 0.75 & 0.38 & 0.79 \\
\hline
\end{tabular}

Correlations between MSI and sum aggregates

\begin{tabular}{lcccccc}
\multirow{2}{*}{ Sums } & \multicolumn{9}{c}{ MSI } \\
\cline { 2 - 7 } M1 (adjusted) & M1 & M2M & M2 & MZM & ALL & M3 \\
M2M & 0.98 & 0.75 & 0.73 & 0.69 & 0.64 & 0.66 \\
M2 & 0.44 & 0.79 & 0.61 & 0.76 & 0.56 & 0.49 \\
MZM & 0.44 & 0.62 & 0.78 & 0.63 & 0.75 & 0.71 \\
ALL & 0.38 & 0.74 & 0.59 & 0.80 & 0.64 & 0.53 \\
M3 & 0.32 & 0.52 & 0.68 & 0.67 & 0.80 & 0.73 \\
& 0.22 & 0.31 & 0.51 & 0.36 & 0.56 & 0.69
\end{tabular}

NOTE: Sample period for calculations excluding M3, January 1967-May 2011; for calculations including M3, January 1967-February 2006. ${ }^{*}$ Change from previous month, percent annual rate.

rate on NOW accounts at commercial banks from January 1974 until January 1982. For February 1982-December 1985, the ceiling rate on NOW accounts is used. The own rate for OCDs at thrift institutions is set to zero before January 1974. For January 1974-December 1985, it is equal to the own rate on OCDs at commercial banks.

\section{Yield-Curve Adjustment of} Small-Denomination Time Deposits

The stock of small-denomination time deposits includes deposits with a range of differ- ent maturities. Farr and Johnson (1985) referred to such components as "composite asset stocks." They constructed own rates for composite asset stocks by yield-curve adjusting the available interest rate data. The yield-curve adjustment consisted of taking an interest rate for a particular maturity and subtracting the corresponding term premium obtained from the Treasury yield curve. The stated purpose of the adjustment was as follows: "Given typical yield-curve relationships, liquidity premiums keep rates on long-maturity assets higher than those on short-maturity assets. Thus, before the rates can be compared, they must 


\section{Figure 6}

\section{Comparison of Year-over-Year Percentage Growth in MSI-ALL and MSI-M3 (1968-2006)}

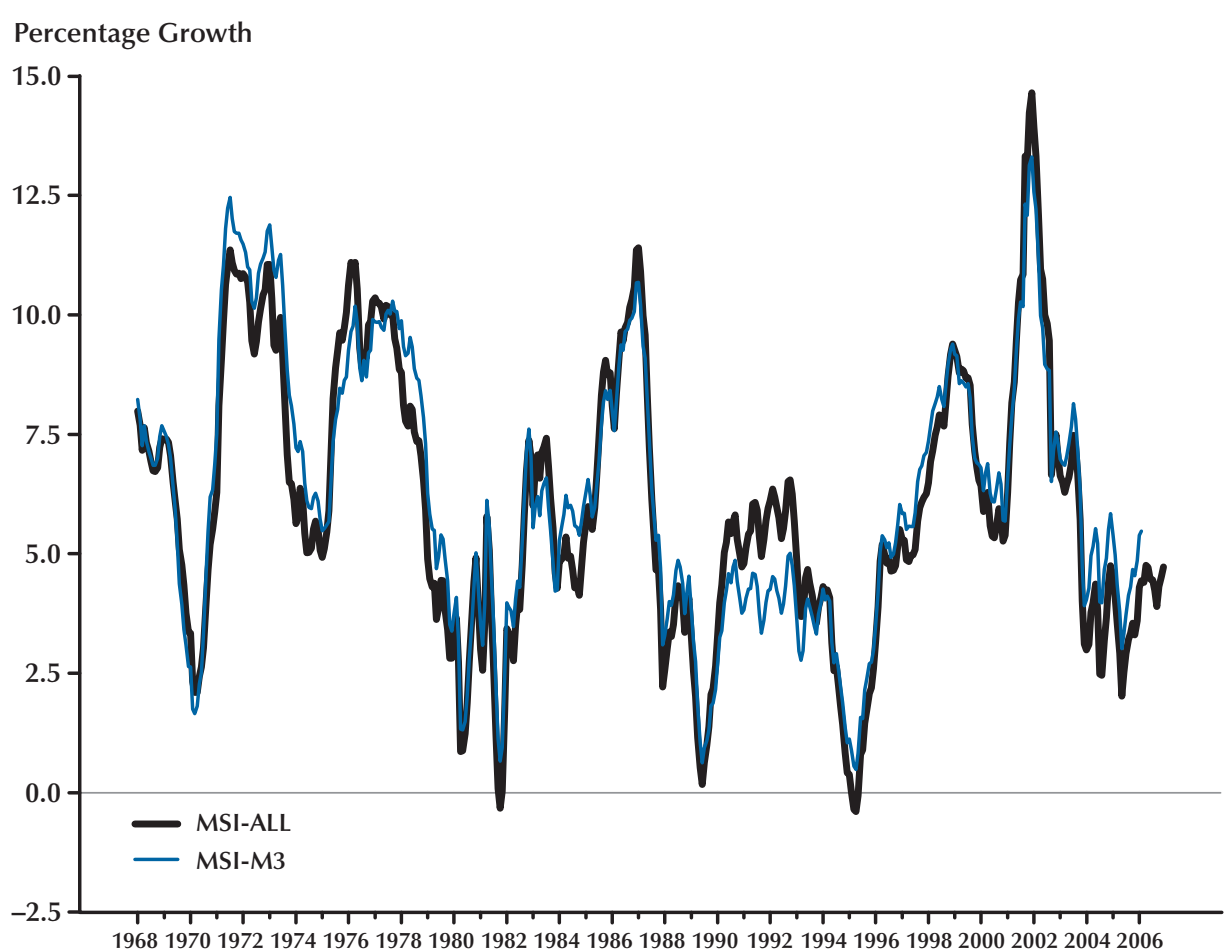

NOTE: Both measures are based on the authors' preferred benchmark rate.

\section{The Discontinuance of M3}

The Federal Reserve Board discontinued publication of the M3 monetary aggregate in early 2006 because "M3 does not appear to convey any additional information about economic activity that is not already embodied in $\mathrm{M} 2$ and has not played a role in the monetary policy process for many years" (H.6 statistical release for March 23, 2006). Data on the non-M2 components of M3 were discontinued at the same time except for institutional MMMFs. Subsequently, some analysts suggested that the Board's assertion regarding the lack of additional information in M3 was in error. To assess the importance of the end of M3, we constructed an MSI-M3 through February 2006 (the most recent feasible date) and compared it with the other five MSI using our preferred benchmark rate. The top panel of Table 3 shows correlations between month-to-month growth rates of the five MSI and MSI-M3. As the table shows, MSI-M3 is most highly correlated with MSI-M2 and MSI-ALL (0.95 and 0.97, respectively). This is also the case for year-over-year growth rates (Figure 6 shows year-over-year growth rates of MSI-ALL and MSI-M3). This lends support to the view that little may have been lost, at least as far as the MSI are concerned, by the discontinuance of M3. On the other hand, it is interesting to note that year-over-year growth of MSI-M2 and MSI-ALL diverged much more than usual in 2010 due to sharp declines in institutional MMMFs (see the discussion in the main text). Figure 7 compares year-over-year growth for MSI-M2 and MSI-ALL for 1988-2011. ${ }^{30}$ Thus, it seems reasonable to infer that an MSI-M3, if it could be constructed for the same period, would display a similar divergence, suggesting that some information value, at least during periods of financial market upheaval, was lost with the discontinuance of M3.

30 The indexes are identical until institutional MMMFs enter in 1974. 
Figure 7

\section{Comparison of Year-over-Year Percentage Growth in MSI-M2 and MSI-ALL (1988-2011)}

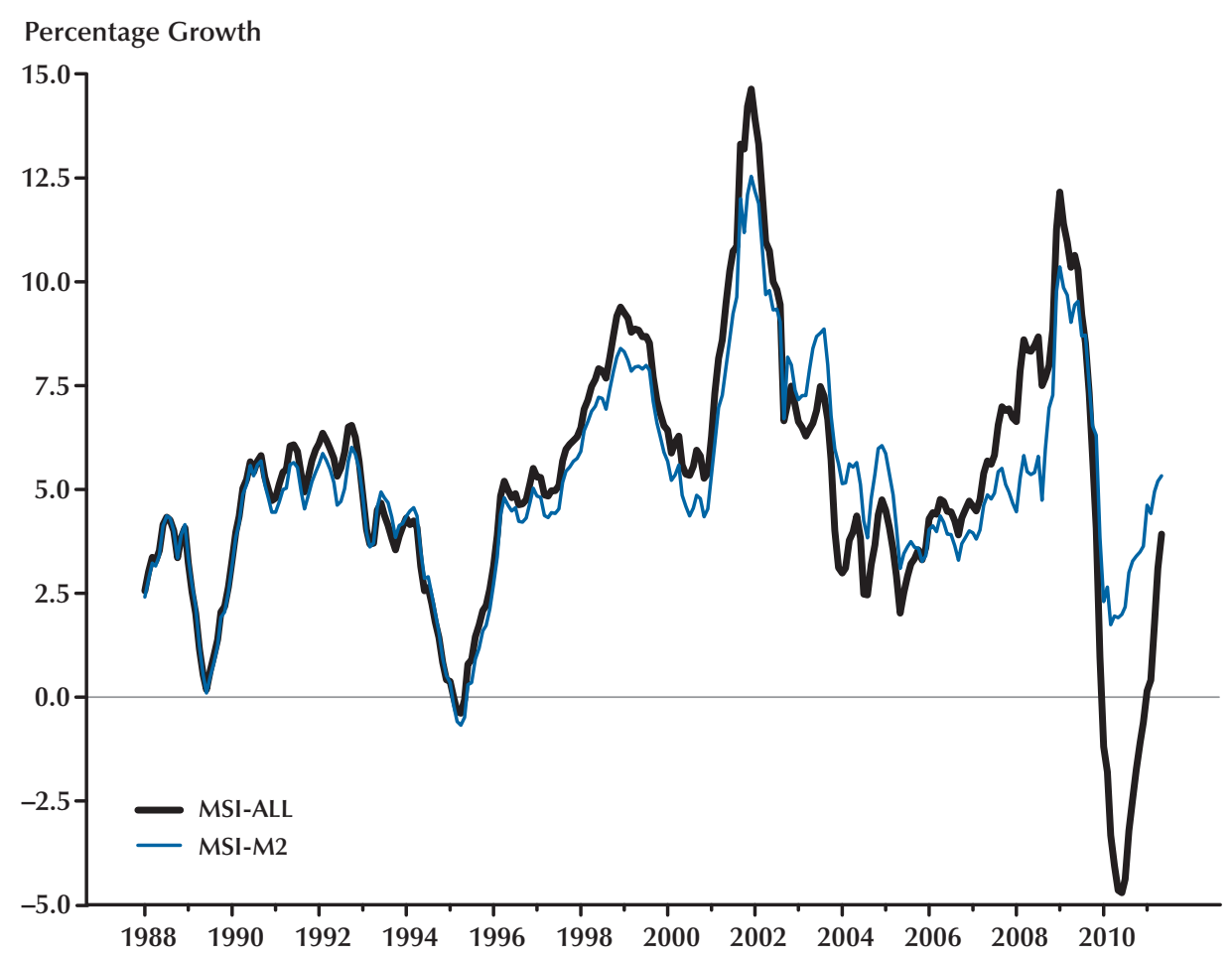

NOTE: Both measures are based on the authors' preferred benchmark rate.

be put on some common basis—the liquidity premiums must be extracted" (Farr and Johnson, 1985, p. 6). They then constructed user costs by using the maximum of the yield-curve-adjusted interest rates as the own rate. Anderson, Jones, and Nesmith (1997c) used a different procedure to calculate user costs of composite asset stocks but their procedure continued to involve the use of yield-curve-adjusted interest rates (see p. 76 of their paper for details).

As of this revision, we have simplified the calculation of the own rates of return on smalldenomination time deposits. As discussed above, we now use the rates of return on 6-month deposits going back to the mid-1970s as the own rates. We do not yield-curve adjust any rates of return, including the short-term yields on the money market instruments included in the upper envelope. To assess the significance of this change, we constructed alternative indexes over the period from August 1991 onward that incorporated yield-curve adjustment. Specifically, we constructed alternative own rates of return on small-denomination time deposits defined as the maximum of the yield-curve-adjusted rates on the available maturities and we yield-curve adjusted all short-term yields included in the upper envelope. These indexes differed very little from our indexes without yield-curve adjustment.

\section{EMPIRICAL ANALYSIS}

This section presents an empirical analysis of our newly revised MSI. Figures 8 and 9 illustrate the short- and long-run growth of the MSI. Figures 10 and 11 show the interaction between the scope of the indexes and the aggregation 
method. We analyze the components of the MSI during the recent financial crisis (2007-09) in Figures 12, 13, and 14. Throughout this section, all figures are based on MSI computed with our preferred benchmark rate.

\section{Long-Run and Short-Run Growth}

Figure 8 shows both month-to-month and year-over-year MSI growth. Generally speaking, movements in the five MSI are similar. During the most recent five years, growth accelerated during 2007 and 2008 in response to Federal Reserve policies, slowed during 2009 (with negative yearover-year growth for MSI-MZM and MSI-ALL due to runoffs in institutional-type MMMFs), and strengthened during 2010 in response to expansionary Federal Reserve policies. The MSI cluster into three groups: MSI-M1, MSI-M2 and MSI-ALL, and MSI-MZM and MSI-M2M.

Figure 9 depicts growth of MSI during four selected decade-long periods. Panel A displays the late 1960s to mid-1970s, a period of increasing inflation. MSI growth slowed during 1969 as Federal Open Market Committee (FOMC) policy tightened, with decreases during 1970 in the levels of MSI-M2M and MSI-MZM. Steady growth resumed late in 1970 as the FOMC eased policy. Panel B includes the 1979-82 period of disinflation and the subsequent recovery. Growth of MSI-M1 slowed little during the period, while growth of both MSI-M2M and MSI-MZM fell rapidly beginning in mid-1978 and remained near zero until the mid-1982 easing of Fed policy. Panel C includes the 1990 recession and its subsequent "jobless recovery" plus the productivity acceleration that started in late 1992. The effects of the Federal Reserve's policy easing in 1991 and policy tightening in 1994 are apparent. Panel D includes the 2001 recession/recovery, the subsequent housing boom and financial crisis, and the Federal Reserve's credit-easing policies during 2008 and its 2009-11 quantitative easing policies. During 2009, two of the indexes, MSI-MZM and MSI-ALL, display absolute decreases due to runoffs in institutional-type MMMFs.

\section{Method of Aggregation Versus Scope of the Aggregate}

This section compares and contrasts the MSI with each other and monetary aggregates constructed by summation of the dollar amounts of the included assets; the latter are denoted as "SUM-M1" and so on. SUM-M2M, SUM-MZM, and SUM-M2 are identical to the monetary aggregates available through FRED. ${ }^{31}$ SUM-M1 is not the same as the Federal Reserve's M1 aggregate because it is retail-sweep adjusted to be comparable with MSI-M1. ${ }^{32}$ SUM-ALL is identical to SUM-M2 plus institutional MMMFs, which are also available through FRED.

Measurement of a monetary aggregate involves two general concepts: the method of aggregation (as an economic index number or via summation of the included assets) and the scope of the aggregate (i.e., which assets are included in the aggregate). With respect to the former, monetary aggregates produced by the Federal Reserve's Board of Governors are summation aggregates: Each is the simple unweighted sum of the dollar values of a selected set of financial assets. The MSI, in contrast, are chain-weighted superlative statistical index numbers. With respect to the scope, both the MSI and summation aggregates are (almost) nested: M1 is a proper subset of $\mathrm{M} 2 \mathrm{M}$ and $\mathrm{M} 2 \mathrm{M}$ is a proper subset of M2. The aggregation-level MZM differs from the level M2M by the inclusion in the former of institutionaltype MMMFs. All the narrower indexes are proper subsets of the aggregate "ALL." From the standpoint of monetary aggregation/index number theory, the two issues are related since superlative index numbers should be constructed over groups of monetary assets that are weakly separable. For further discussion of this view, see Barnett (1982), Swofford and Whitney (1991), and Belongia (1996).

Figure 10 shows a scatterplot matrix of monthto-month percentage growth rates of the five MSI; correlations between the MSI are shown in the

\footnotetext{
${ }^{31}$ FRED (Federal Reserve Economic Data); available through the St. Louis Fed's website (http://research.stlouisfed.org/fred2/).

32 SUM-M1, as measured here, equals the Federal Reserve's M1 aggregate plus the estimated amount of retail sweeps; Dutkowsky, Cynamon, and Jones (2006) and Cynamon, Dutkowsky, and Jones (2006) refer to this as M1RS (M1 plus retail sweeps).
} 


\section{Figure 8}

\section{MSI Growth Rates}

Month-to-Month Change (February 1967-May 2011)
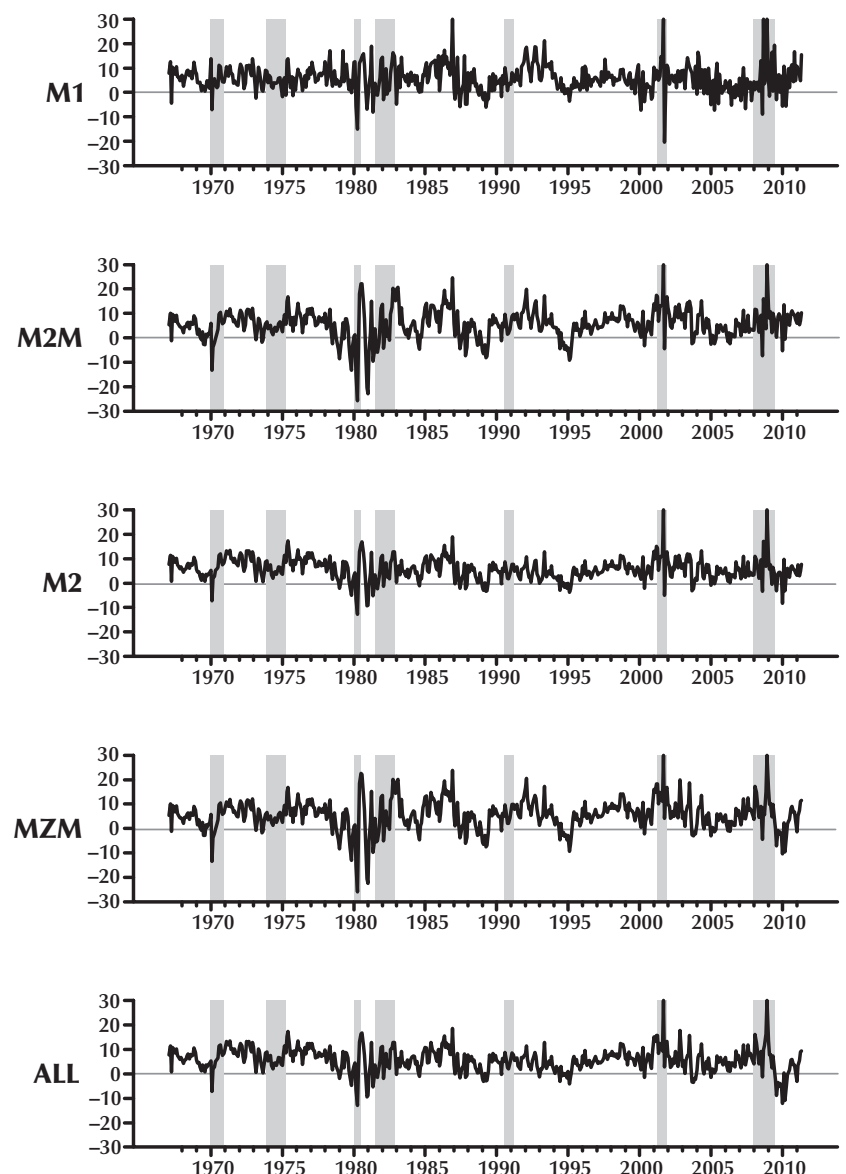

Year-to-Year Change (January 1968-May 2011)
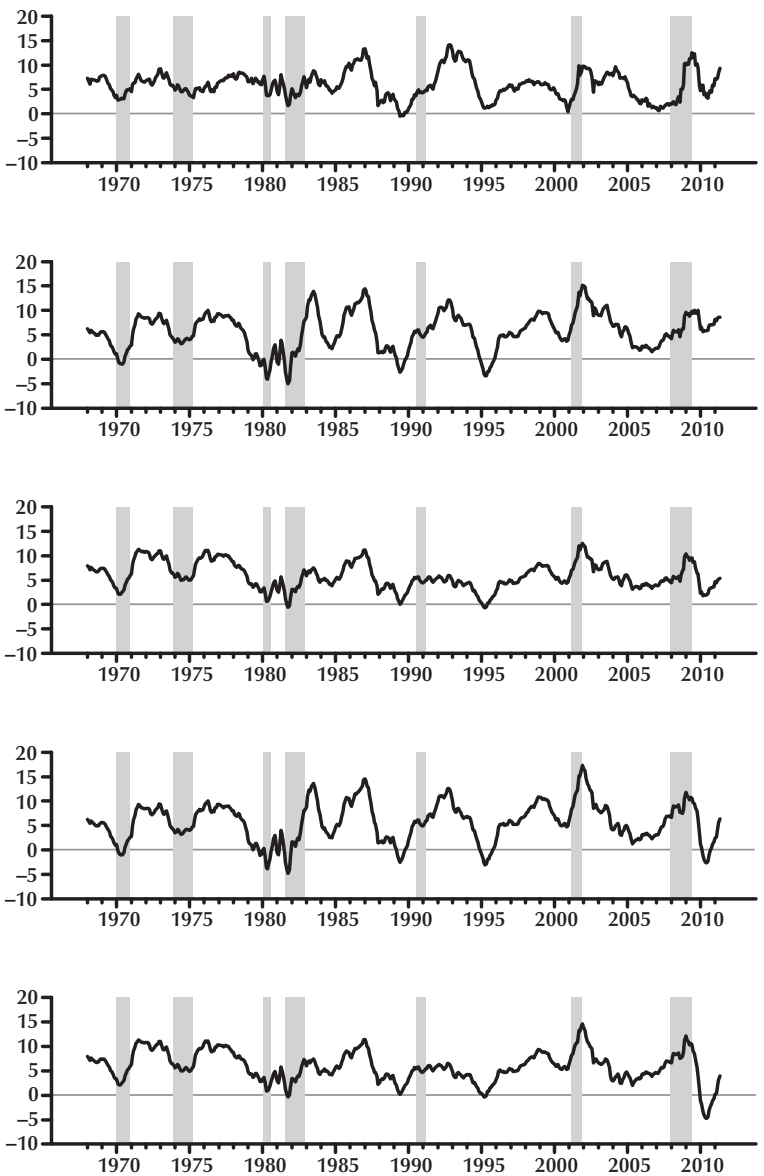

NOTE: The left panels show month-to-month percentage change, at an annual rate, in each MSI aggregate; changes in excess of \pm 30 percent are excluded. Excluded dates and values are M1, 1986:12 (32.4 percent), 2001:09 (44.8 percent), 2008:09 (32.9 percent), 2008:12 (50.9 percent); M2M, 2001:09 (37.2 percent), 2008:12 (32.5 percent); M2, 2001:09 (32.7 percent), 2008:12 (31.1 percent); MZM, 2001:09 (38.9 percent), 2008:12 (32.8 percent); ALL, 2001:09 (34.7 percent), 2008:12 (31.7 percent). Right panels show year-to-year percentage change, monthly (no truncated points are omitted). Absolute decreases in MSI-MZM and MSI-ALL during 2010 were due to sharp decreases in institutional-type MMMFs. Intervals between National Bureau of Economic Research (NBER) business cycle peaks and troughs are shaded. 


\section{Figure 9}

\section{Growth of the MSI Aggregates (selected decades)}

A. Jan 1967-Dec 1976

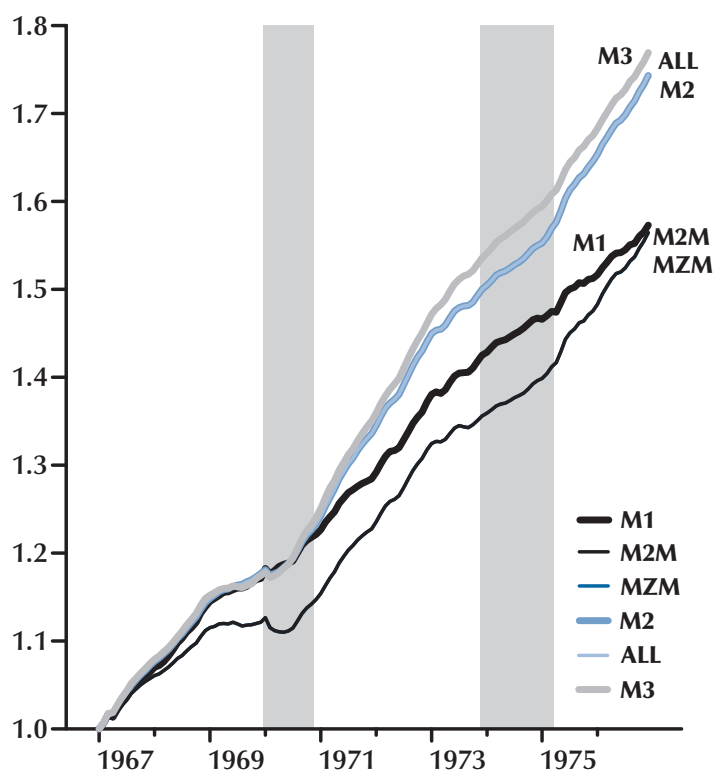

C. Jan 1989-Dec 1998

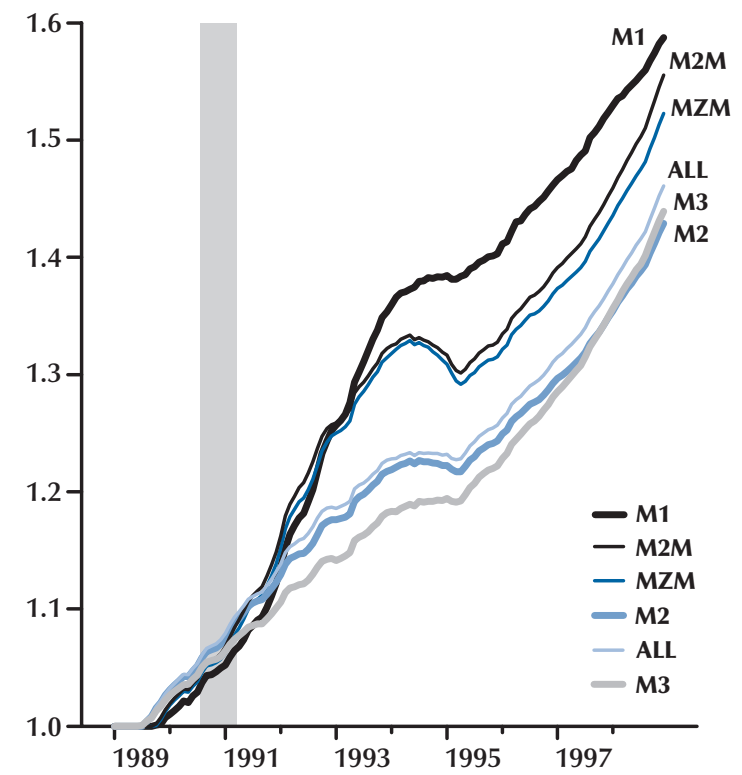

B. Jan 1978-Dec 1987

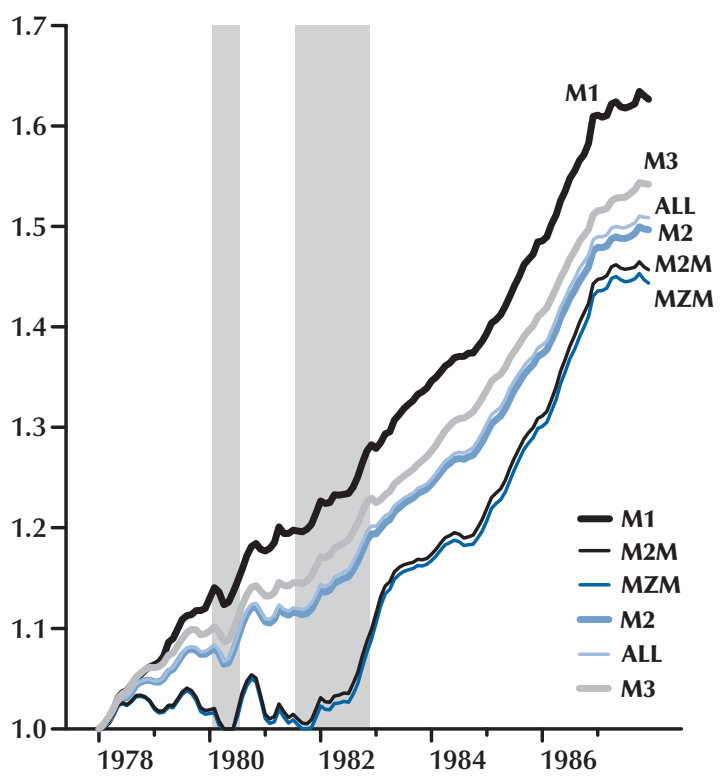

D. Mar 2001-Feb 2011

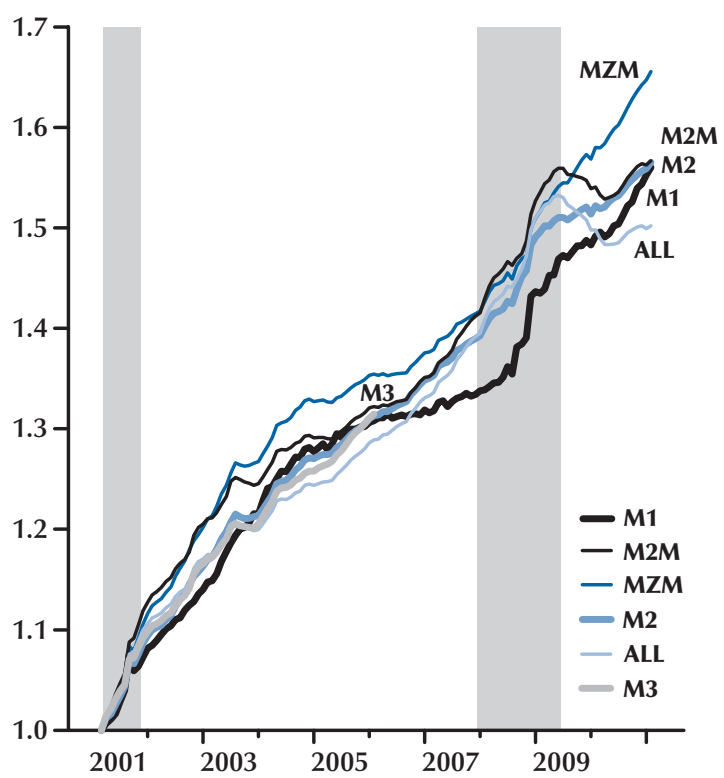

NOTE: Each panel compares the path of (the log of) the specified MSI aggregate during a selected decade-long period. Intervals between NBER business cycle peaks and troughs are shaded. For A, log levels, January $1967=10$. For B, log levels, January $1978=1.0$. For C, $\log$ levels, January $1989=1.0$. For D, $\log$ levels, March $2001=1.0$. 


\section{Figure 10}

\section{MSI Indexes (January 1967-April 2011)}

MSI
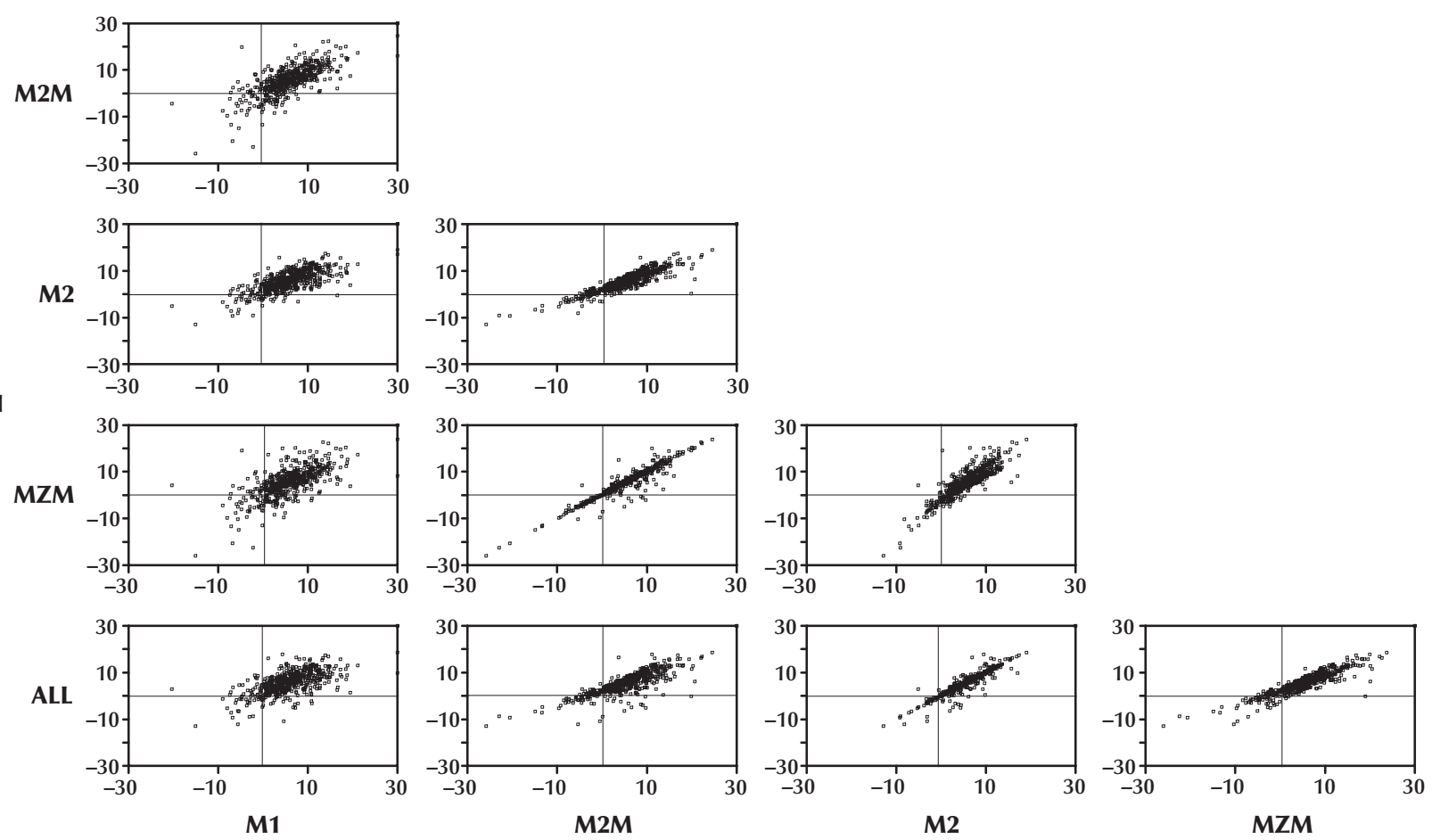

MSI

NOTE: Each panel compares the monthly growth of the two specified MSI. The MSI aggregates are adjusted for the effects of retail deposit sweep programs by removing such deposits from savings deposits and including them in checkable deposits. Monthly growth rates in excess of 30 percent are excluded from the chart; see the footnote to Figure 8 for a list of the excluded points.

top panel of Table 3. We note that M3 is included in Table 3 but not in the associated figures. Among the MSI, the lowest correlations involve MSI-M1 (first column). Aside from MSI-M1, all of the MSI are mutually highly correlated. The correlation between MSI-M2M and MSI-MZM is 0.95 and that between MSI-M2 and MSI-ALL is 0.94. The middle panel of Table 3 shows the correlations between the sum aggregates, which (except for M2M and MZM) are lower than the correlations among the MSI. Figure 11 shows a scatterplot matrix comparing the month-to-month growth rates of the MSI and the corresponding summation aggregates; corresponding correlations are shown in the bottom panel of Table 3. When comparing SUM aggregates with the MSI, a general finding is that the SUM aggregates are all most highly correlated with the MSI constructed over the same components. ${ }^{33}$ The correlation is highest (0.98) between SUM-M1 (adjusted for retail deposit sweeps) and MSI-M1. For M2M, M2, MZM, and ALL, the correlations between the SUM aggregate and the comparable MSI are between 0.78 and 0.80 . For M3, it is 0.69. SUM-M1 (adjusted for retail sweeps) displays modest positive correlation with all of the other MSI as well (0.64 to 0.75). Other SUM aggregates show modest positive correlation with at least some MSI, although correlations involving MSI-M1 are all low. For example, correlations between SUM-M2

${ }^{33}$ Except for M3, the MSI are also most highly correlated with the SUM aggregate constructed over the same components. 


\section{Figure 11}

\section{MSI Indexes Versus Sum Money Aggregates (January 1967-April 2011)}
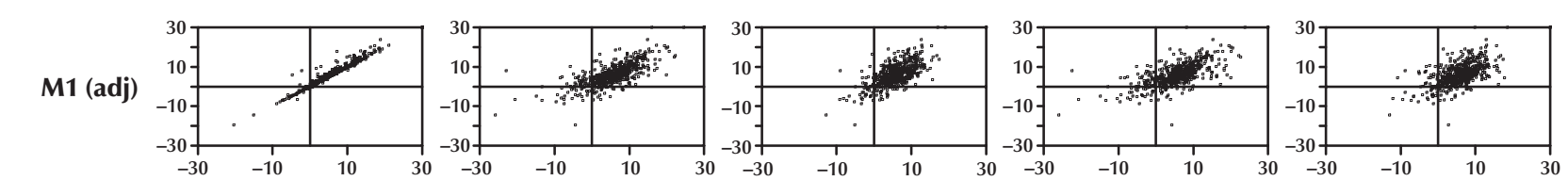

M2M
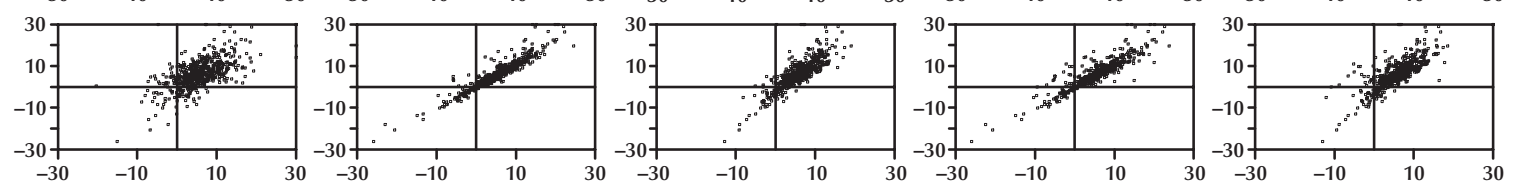

SUMS
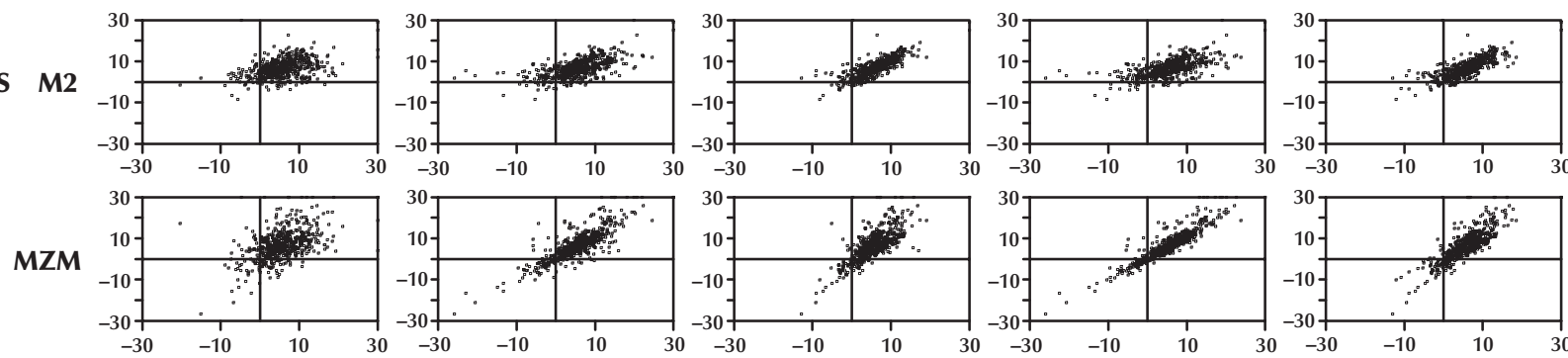

ALL
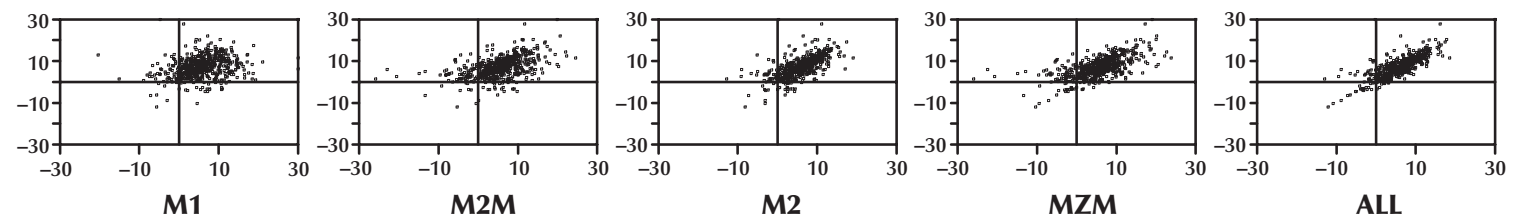

MSI

NOTE: Each panel compares the monthly growth of the specified MSI and the corresponding simple-sum monetary aggregate. The sum aggregate M1 (adj) and all MSI are adjusted for the effects of retail deposit sweep programs as described in the text. Excluded points for the MSI are listed in the notes of Figure 8. Excluded points for the Sum aggregates are for M1 adjusted for retail sweeps, 1986:12 (32.7), 2001:09 (43.2), 2008:09 (32.5), 2008:12 (50.1); for M2M, 1982:12 (44.4), 1983:01 (123.8), 1983:02 (79.1), 1983:03 (35.2), $2001: 09$ (32.7), 2008:12 (30.8); for M2, 1983:01 (33.40); for MZM, 1980:07 (31.4), 1981:04 (30.1), 1982:12 (41.0), 1983:01 (116.9), 1983:02 (75.7), 1983:03 (32.5), 2001:09 (37.3), 2008:02 (31.4), 2008:12 (31.6); for ALL, 1983:01 (31.7), 2001:09 (30.2), 2008:12 (30.1). Values in parentheses indicate percent.

and MSI other than MSI-M1 range from 0.62 to 0.75. It is interesting to note all of the MSI, except MSI-M3, are less highly correlated with MSI-M1 than they are with the SUM aggregate constructed over the same components (for MSI-M3, the correlations are the same). Thus, the choice between M1 and a broader level of aggregation clearly matters more than the method of aggregation.

\section{A Case Study of MSI Components During the 2007-2009 Financial Crisis}

Economic theory suggests that the MSI provide a superior measure of the flow of monetary services that households and firms derive from holding monetary assets. In this section, we briefly survey the behavior of component quantities of the MSI and their user costs during the financial crisis; more complete modeling is a topic for future research. The construction of the MSI provides data beyond quantity indexes, including measures of the user cost of monetary services (essentially, the price of owning immediately available funds plus the cost of positioning an asset portfolio so that such funds are readily available when needed) that are interesting to examine because the recent financial crisis was largely a "liquidity" crisis in 


\section{Figure 12}

\section{Major Components of MSI}
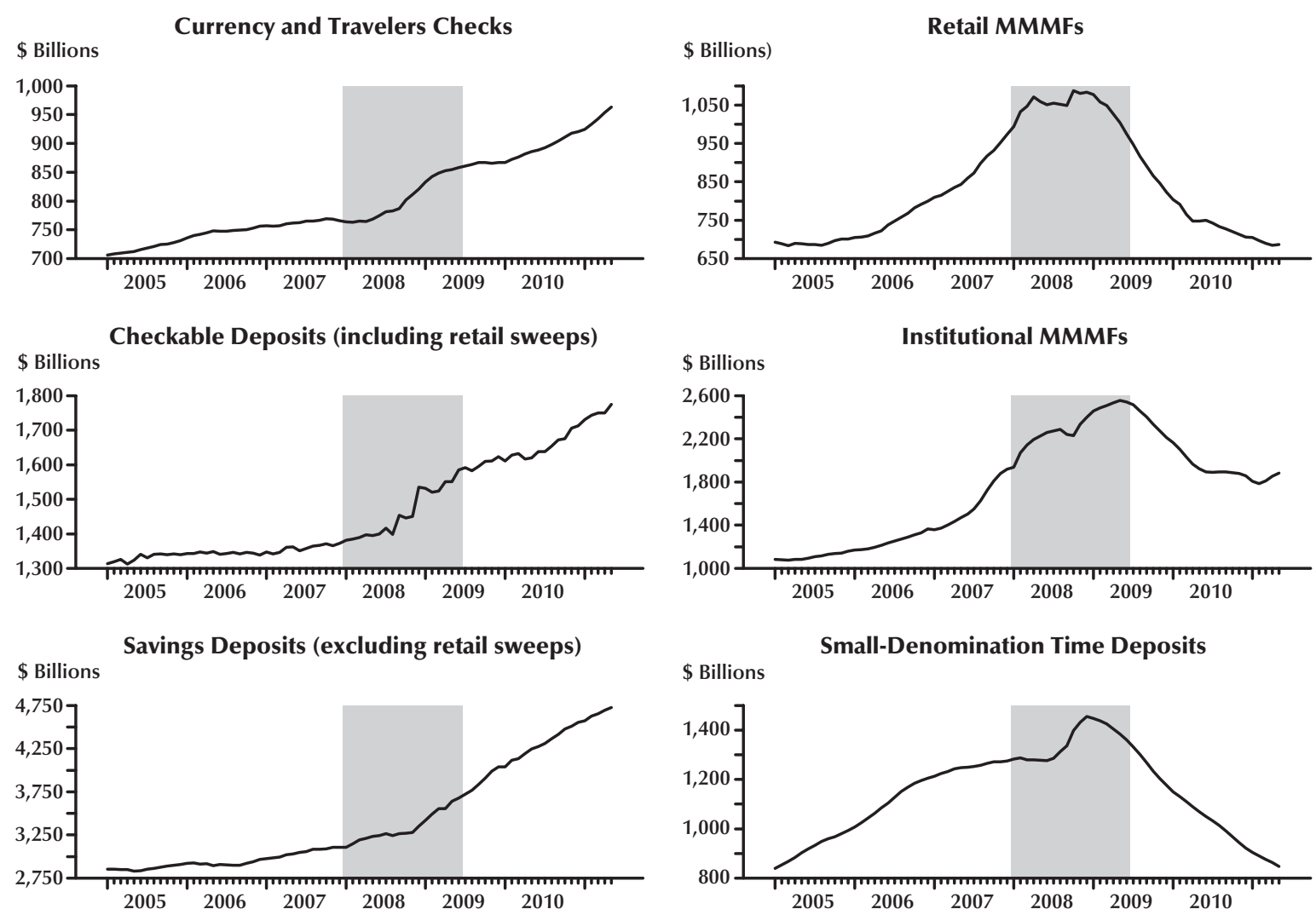

NOTE: Each panel shows the nominal quantity (in billions of current dollars) of a group of monetary assets included in the MSI. Checkable deposits includes, and savings deposits excludes, the amount of deposits in retail deposit sweep programs.

which the functioning of short-term money and financial markets was impaired.

Figure 12 shows changes in the component quantities of the MSI. For checkable deposits (demand deposits and OCDs), savings, and smalldenomination time deposits, we have summed the amounts at commercial banks and thrift institutions, calculating the user costs by dividing the corresponding summed expenditures by the sum of the quantities. There is a clear break in all series circa September 2008 (when Lehman Brothers filed for bankruptcy, the federal government rescued AIG, and the shadow banking system largely shut down). ${ }^{34}$ With respect to individual components during late 2008, the sharp increase in checkable deposits reflects, in part, extension by the FDIC in October 2008 of deposit insurance without limit to non-interest-bearing checkable deposits. Increases in savings and small-denomination time deposits likely reflect flight to quality since these deposits are FDIC insured. Small dimples in MMMF shares likely reflect shaken investor confidence before the federal government's October 2008 de facto extension of deposit insurance to shares in these funds. During 2009 and 2010, steep runoffs in the components except currency, checkable deposits, and savings deposits are

\footnotetext{
34 Anderson and Gascon (2009) examine the 2008 sudden stop in the asset-backed commercial paper market, the heart of the U.S. "shadow" banking system.
} 
Figure 13

\section{Real User Cost of Monetary Services by Component}

\section{Currency and Travelers Checks}

Percent Annual Rate, Monthly

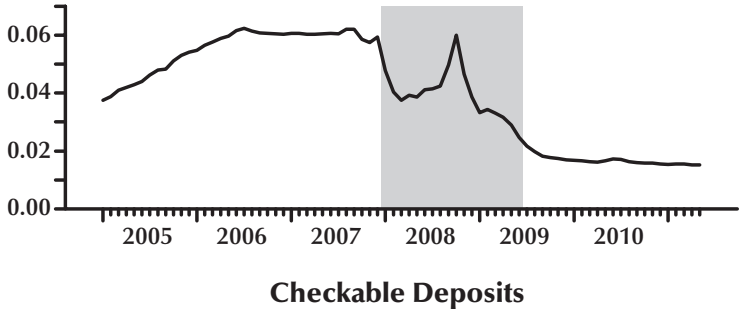

Percent Annual Rate, Monthly

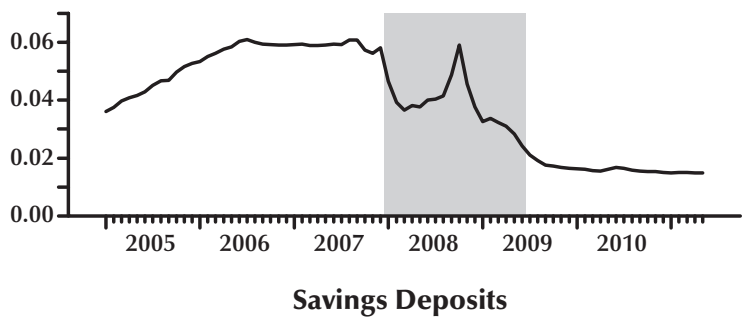

Percent Annual Rate, Monthly

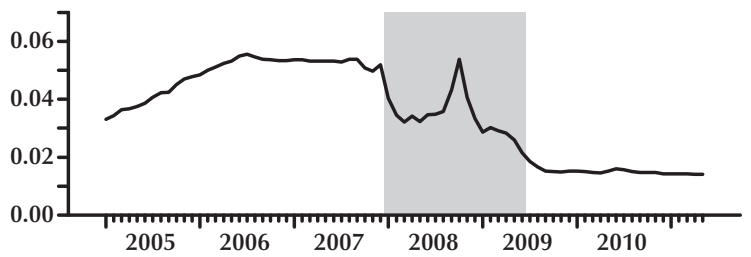

Retail MMMFs

Percent Annual Rate, Monthly

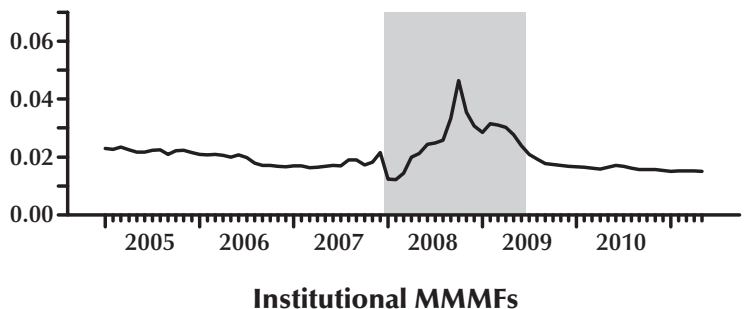

Percent Annual Rate, Monthly

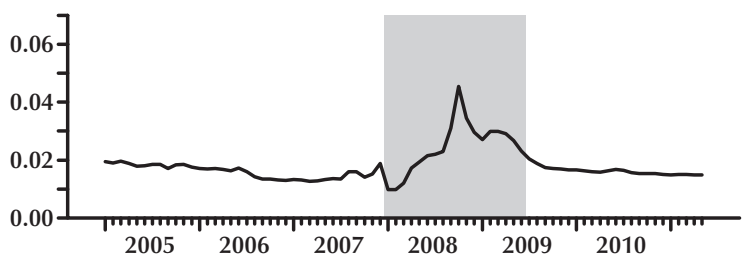

Small-Denomination Time Deposits

Percent Annual Rate, Monthly

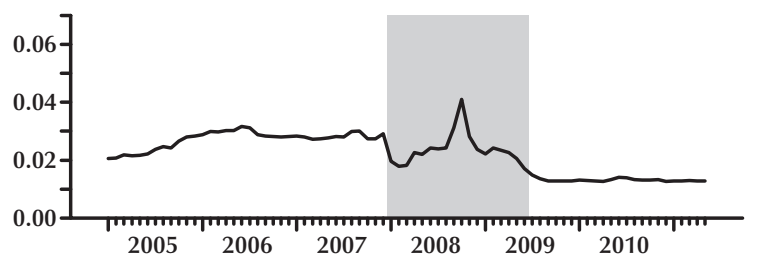

NOTE: Each panel shows the real user cost of the monetary services obtained through the specified group of assets. Within each group, the user costs are simple arithmetic averages of the user costs of the components within that group.

apparent; the trough in economic activity occurred during the second quarter of 2009 and the stock market low point was in March 2009.

Whereas economic theory suggests that all components of an MSI furnish monetary services (either as medium of exchange or as an asset readily convertible to medium of exchange), the user costs (prices) of monetary assets differ because they earn different rates of return. Figure 13 shows the real user costs. Three major shifts are apparent. First, the user costs decreased sharply in late 2007-early 2008, in part due to FOMC policy actions. Second, the user costs increased almost steadily during 2008 before jumping sharply during September when short-term financial markets shut down. Third, user costs decreased sharply and then steadily during 2009, again in response to FOMC policy action. During the financial crisis, the user cost of monetary services accurately tracked the scarcity of liquidity due to impaired short-term money markets. Indeed, increases in the price of monetary services (i.e., the price of liquidity) reinforce Federal Reserve Chairman Ben Bernanke's argument that immediate relief of financial market stress (“credit easing”) was essential. ${ }^{35}$

\footnotetext{
${ }^{35}$ Anderson and Gascon (2011) survey many such market assistance programs and review evidence regarding their role in preventing a slide into economic depression.
} 


\section{Figure 14}

\section{Expenditure Shares of Monetary Services}
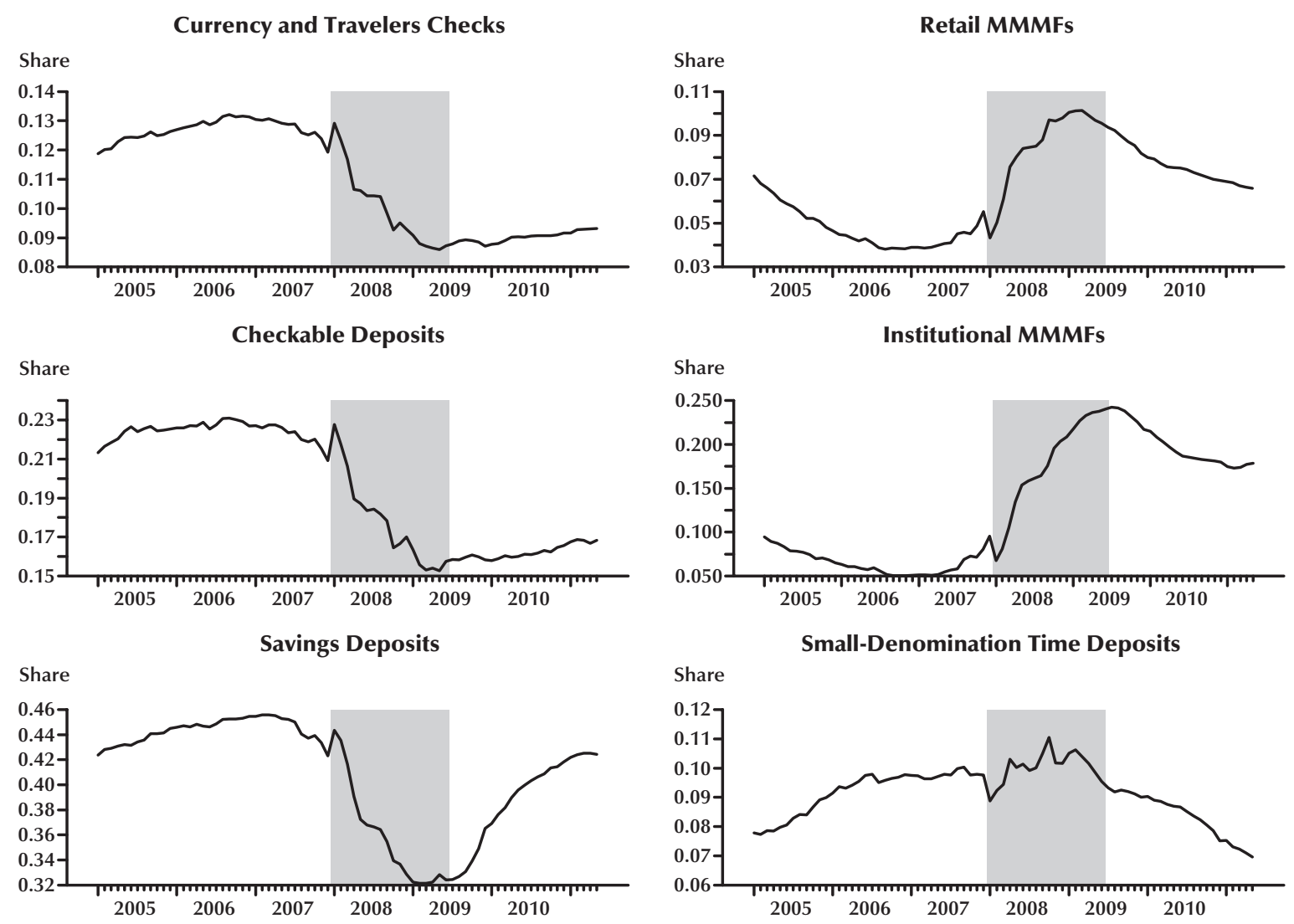

NOTE: Each panel shows expenditures on a set of components from MSI-ALL as a share of total expenditure on MSI-ALL. Expenditures incurred to obtain the monetary services furnished by each group of assets equal the sum (across the assets in the group) of the products of each asset's real user cost times the asset's nominal quantity (or equivalently, the product of each asset's nominal user cost times the real quantity of each asset).

Figure 14 combines information from Figures 12 and 13 to examine fluctuations in expenditures on money services during the financial crisis.

Note that the behavior of component expenditure shares depends on the price elasticity of demanda component's share might increase, decrease, or be unchanged when its price increases. In the left column of the figure, the shares of expenditure (on monetary services) corresponding to the three most-liquid assets decreased throughout 2008. In contrast, the expenditure shares for MMMFs increased throughout 2008. The expenditure share for small-denomination time deposits increased slightly during 2008, followed by a sharp decrease during 2009. Deeper understanding of these expenditure share patterns is a topic for future research. ${ }^{36}$

\section{SUMMARY AND CONCLUSIONS}

The revised MSI and the underlying data used to construct them as presented in this article are

${ }^{36}$ A standard way to model the expenditure share system would be to estimate a demand systems model for the monetary assets. Jones et al. (2008), for example, estimate a Fourier flexible functional form model for the components of MSI-M2. 
valuable resources to empirical economists interested in the role that money plays in the economy. This revision to the MSI includes a number of changes that should improve the quality of the underlying data. We now adjust the savings and checkable deposit components for the effects of retail sweep programs and have improved the measures of savings and small-denomination time deposit rates in the Regulation Q era. We also introduce a new benchmark rate, defined as the largest rate in a set of rates that includes the own rates of the components of the broadest index and yields on selected short-term money market rates (the upper envelope) plus a modest liquidity premium. Previously the benchmark rate was defined by including the Baa bond yield in the upper envelope and not adding a liquidity premium. We believe that this new benchmark rate improves on the previous practice since recent literature has criticized using long-term bond yields to measure the benchmark rate (e.g., Stracca, 2004). Nevertheless, the benchmark rate remains one of the most problematic aspects of the Divisia approach in terms of being as much a conceptual issue as an empirical one.

Several issues raised in this paper relate to the components of M1. A major problem with the official M1 monetary aggregate is, of course, retail sweeping of transaction deposits. Although not addressed in this paper, commercial sweeping of demand deposits further complicates interpretation of the M1 aggregate (see Jones, Dutkowsky, and Elger, 2005, and Dutkowsky, Cynamon, and Jones, 2006). Another problem concerns implicit remuneration of demand deposits. Within M1, only OCDs are explicitly remunerated. Before the paper by Anderson, Jones, and Nesmith (1997c), the builders of Divisia monetary aggregates proceeded as if demand deposits held by businesses were remunerated at a rate equal to the short-term commercial paper rate adjusted for statutory reserve requirements; the data used to distinguish between business and household demand deposits were discontinued in 1990. Our decision to not include implicit returns on demand deposits is based on this lack of data. We are concerned, in particular, about whether MSI-M1 provides much useful information beyond what is provided by a sweep-adjusted version of its simple sum counterpart (e.g., Figure 11, row 1). Moreover, the main advantage of the Divisia approach relates to the construction of broader aggregates. As Lucas (2000, pp. 270-71) has argued, "I share the widely held opinion that M1 is too narrow an aggregate for this period [the 1990s], and I think that the Divisia approach offers much the best prospects for resolving the difficulty."

Finally, a number of analysts have argued that the Federal Reserve's 2006 decision to discontinue publication of its M3 monetary aggregate significantly constrained subsequent monetary analyses. We found that the growth rates of MSIM2 and MSI-ALL are both highly correlated with growth rates of MSI-M3 when it can be computed providing some reassurance with respect to the discontinuance of M3. On the other hand, growth rates of MSI-M2 and MSI-ALL diverged much more than usual in 2010, suggesting that MSI-M3 might have contained some additional information in recent years. 


\section{REFERENCES}

Anderson, Richard G. "Sweeps Distort M1 Growth.” Federal Reserve Bank of St. Louis Monetary Trends, November 1995; http://research.stlouisfed.org/aggreg/sweeps.html.

Anderson, Richard G. and Buol, Jason. "Revisions to User Costs for the Federal Reserve Bank of St. Louis Monetary Services Indices.” Federal Reserve Bank of St. Louis Review, November/December 2005, 87(6), pp. 735-49; http://research.stlouisfed.org/publications/review/05/11/AndersonBuol.pdf.

Anderson, Richard G. and Gascon, Charles S. "The Commercial Paper Market, the Fed, and the 2007-2009 Financial Crisis.” Federal Reserve Bank of St. Louis Review, November/December 2009, 91(6), pp. 589-612; http://research.stlouisfed.org/publications/review/09/11/Anderson.pdf.

Anderson, Richard G. and Gascon, Charles S. "A Closer Look: Assistance Programs in the Wake of the Crisis." Federal Reserve Bank of St. Louis Regional Economist, January 2011, pp. 4-10; http://stlouisfed.org/publications/pub assets/pdf/re/2011/a/bailouts.pdf.

Anderson, Richard G.; Jones, Barry E. and Nesmith, Travis D. "Introduction to the St. Louis Monetary Services Index Project.” Federal Reserve Bank of St. Louis Review, January/February 1997a, 79(1), pp. 25-29; reprinted in Barnett and Serletis (2000).

Anderson, Richard G.; Jones, Barry E. and Nesmith, Travis D. "Monetary Aggregation Theory and Statistical Index Numbers." Federal Reserve Bank of St. Louis Review, January/February 1997b, 79(1), pp. 31-51.

Anderson, Richard G.; Jones, Barry E. and Nesmith, Travis D. "Building New Monetary Services Indices: Concepts, Data and Methods.” Federal Reserve Bank of St. Louis Review, January/February 1997c, 79(1), pp. 53-82.

Anderson, Richard G. and Rasche, Robert H. "Retail Sweep Programs and Bank Reserves, 1994-1999.” Federal Reserve Bank of St. Louis Review, January/February 2001, 83(1), pp. 51-72;

http://research.stlouisfed.org/publications/review/01/0101ra.pdf.

Barnett, William A. “The User Cost of Money.” Economics Letters, 1978, 1(2), pp. 145-49.

Barnett, William A. "Economic Monetary Aggregates: An Application of Index Numbers and Aggregation Theory." Journal of Econometrics, Summer 1980, 14(1), pp. 11-48.

Barnett, William A. "The Optimal Level of Monetary Aggregation.” Journal of Money, Credit, and Banking, 1982, 14(4 Part 2), pp. 687-710.

Barnett, William A. "The Microeconomic Theory of Monetary Aggregation," in William A. Barnett and Kenneth J. Singleton, eds., New Approaches to Monetary Economics: Proceedings of the Second International Symposium in Economic Theory and Econometrics. New York: Cambridge University Press, 1987, pp. 115-68.

Barnett, William A. "Aggregation-Theoretic Monetary Aggregation Over the Euro Area When Countries Are Heterogeneous.” ECB Working Paper No. 260, European Central Bank, September 2003; www.ecb.int/pub/pdf/scpwps/ecbwp260.pdf.

Barnett, William A. "Multilateral Aggregation-Theoretic Monetary Aggregation Over Heterogeneous Countries." Journal of Econometrics, February 2007, 136(2), pp. 457-82. 


\section{Anderson and Jones}

Barnett, William A. Getting It Wrong: How Faulty Monetary Statistics Undermine the Fed, the Financial System, and the Economy. Cambridge, MA: MIT Press, forthcoming.

Barnett, William A. and Chauvet, Marcelle. "How Better Monetary Statistics Could Have Signaled the Financial Crisis.” Journal of Econometrics, March 2011, 161(1), pp. 6-23.

Barnett, William A.; Offenbacher, Edward and Spindt, Paul. "New Concepts of Aggregated Money." Journal of Finance, May 1981, 36(2), pp. 497-505.

Barnett, William A. and Serletis, Apostolos, eds. Theory of Monetary Aggregation. Amsterdam: North-Holland, 2000.

Barnett, William A. and Spindt, Paul A. "Divisia Monetary Aggregates: Compilation, Data, and Historical Behavior.” Board of Governors of the Federal Reserve System Staff Study No. 116, May 1982.

Belongia, Michael T. "Measurement Matters: Recent Results from Monetary Economics Reexamined.” Journal of Political Economy, October 1996, 104(5), pp. 1065-83.

Bissoondeeal, Rakesh K.; Jones, Barry E.; Binner, Jane M. and Mullineaux, Andrew W. "Household-Sector Money Demand for the UK.” The Manchester School, September 2010, 78(s1), pp. 90-113.

Board of Governors of the Federal Reserve System. 86th Annual Report 1999. Washington, DC: Federal Reserve Board, 2000; www.federalreserve.gov/boarddocs/rptcongress/annual99/ann99.pdf.

Cynamon, Barry Z; Dutkowsky, Donald H. and Jones, Barry E. "Redefining the Monetary Aggregates: A Clean Sweep.” Eastern Economic Journal, Fall 2006, 32(4), pp. 661-72.

Diewert, W.E. "Intertemporal Consumer Theory and the Demand for Durables." Econometrica, May 1974, 42(3), pp. 497-516.

Diewert, W.E. "Exact and Superlative Index Numbers.” Journal of Econometrics, May 1976a, 4(2), pp. 115-45.

Diewert, W.E. "Harberger's Welfare Indicator and Revealed Preference Theory.” American Economic Review, March 1976b, 66(1), pp. 143-52.

Diewert, W.E. “Aggregation Problems in the Measurement of Capital,” in Dan Usher, ed., The Measurement of Capital. Chap. 11. Chicago: University of Chicago Press, 1980, pp. 433-538.

Diewert, W.E. "The Economic Theory of Index Numbers: A Survey,” in W.E. Diewert and A.O. Nakamura, eds., Essays in Index Number Theory. Volume 1, Chap. 7. Amsterdam: North-Holland, 1993, pp. 163-208; http://faculty.arts.ubc.ca/ediewert/indexch7.pdf.

Donovan, Donal J. "Modeling the Demand for Liquid Assets: An Application to Canada." International Monetary Fund IMF Staff Papers, 1978, 25(4), pp. 676-704.

Drake, Leigh M. and Mills, Terence C. "A New Empirically Weighted Monetary Aggregate for the United States." Economic Inquiry, January 2005, 43(1), pp. 138-57.

Drake, Leigh M. and Fleissig, Adrian R. "Adjusted Monetary Aggregates and UK Inflation Targeting.” Oxford Economic Papers, January 2006, 58(4), pp. 681-705. 
Duca, John V. and VanHoose, David D. "Recent Developments in Understanding the Demand for Money." Journal of Economics and Business, 2004, 56(4), pp. 247-72.

Dutkowsky, Donald H. and Cynamon, Barry Z. "Sweep Programs: The Fall of M1 and the Rebirth of the Medium of Exchange.” Journal of Money, Credit, and Banking, April 2003, 35(2), pp. 263-79.

Dutkowsky, Donald H.; Cynamon, Barry Z. and Jones, Barry E. "U.S. Narrow Money for the Twenty-First Century.” Economic Inquiry, January 2006, 44(1), pp. 142-52.

Elger, C. Thomas; Jones, Barry E. and Nilsson, Birger. "Forecasting with Monetary Aggregates: Recent Evidence for the United States." Journal of Economics and Business, 2006, 58(5-6), pp. 428-46.

Elger, C. Thomas; Jones, Barry E.; Edgerton, David L. and Binner, Jane M. "A Note on the Optimal Level of Monetary Aggregation in the United Kingdom.” Macroeconomic Dynamics, 2008, 12(1), pp. 117-31.

Farr, Helen T. and Johnson, Deborah. "Revisions in the Monetary Services (Divisia) Indexes of the Monetary Aggregates.” Board of Governors of the Federal Reserve System Staff Study No. 147, 1985; http://babel.hathitrust.org/cgi/pt?id=mdp.35128000918134.

Federal Reserve Statistical Release: H.6-Money Stock Measures. "Discontinuance of M3.” March 23, 2006; www.federalreserve.gov/releases/h6/20060323/.

Fisher, Paul; Hudson, Suzanne and Pradhan, Mahmood. "Divisia Measures of Money.” Bank of England Quarterly Bulletin, May 1993, 33(2), pp. 240-55.

Gilbert, R. Alton. "Requiem for Regulation Q: What It Did and Why It Passed Away.” Federal Reserve Bank of St. Louis Review, February 1986, pp. 22-37; http://research.stlouisfed.org/publications/review/86/02/Requiem Feb1986.pdf.

Goldfeld, Stephen M. and Sichel, Daniel E. "The Demand for Money,” in B.M. Friedman and F.H. Hahn, eds., Handbook of Monetary Economics. Volume 1, Chap. 8. Amsterdam: Elsevier Science, 1990, pp. 299-356.

Hancock, Matthew. “Divisia Money.” Bank of England Quarterly Bulletin, Spring 2005, pp. 39-46; www.bankofengland.co.uk/publications/quarterlybulletin/qb050103.pdf.

Hill, Robert J. "Superlative Index Numbers: Not All of Them Are Super.” Journal of Econometrics, January 2006, 130(1), pp. 25-43.

Holmström, Bengt and Tirole, Jean. Inside and Outside Liquidity. Cambridge, MA: MIT Press, 2011.

Jones, Barry E.; Dutkowsky, Donald H. and Elger, C. Thomas. "Sweep Programs and Optimal Monetary Aggregation." Journal of Banking and Finance, 2005, 29(2), pp. 483-508.

Jones, Barry E.; Fleissig, Adrian R.; Elger, C. Thomas and Dutkowsky, Donald H. "Retail Sweep Programs and Monetary Asset Substitution.” Economics Letters, 2008, 99(1), pp. 159-63.

King, Robert G. and Plosser, Charles I. "Money, Credit and Prices in a Real Business Cycle." American Economic Review, June 1984, 74(3), pp. 363-80.

Kohn, Donald. "Regulatory Reform Proposals." Testimony before the Committee on Banking, Housing, and Urban Affairs, U.S. Senate. June 22, 2004; www.bis.org/review/r040713g.pdf. 


\section{Anderson and Jones}

Lefever, David M. “Survey of Time and Savings Deposits at Commercial Banks, January 1979.” Federal Reserve Bulletin, May 1979, 65(5), pp. 387-92;

http://fraser.stlouisfed.org/publications/frb/1979/download/61185/frb 051979.pdf.

Lucas, Robert E. Jr. “Inflation and Welfare.” Econometrica, March 2000, 68(2), pp. 247-74.

Mahoney, Patrick I. “The Recent Behavior of Demand Deposits.” Federal Reserve Bulletin, April 1988, pp. 195-208; http://fraser.stlouisfed.org/publications/frb/page/32405/download/65063/32405 1985-1989.pdf.

Ruebling, Charlotte E. “The Administration of Regulation Q.” Federal Reserve Bank of St. Louis Review, February 1970, pp. 29-40; http://research.stlouisfed.org/publications/review/70/02/Administration Feb1970.pdf.

Stracca, Livio. "Does Liquidity Matter? Properties of a Divisia Monetary Aggregate in the Euro Area." Oxford Bulletin of Economics and Statistics, 2004, 66(3), pp. 309-31.

Swofford, James L. and Whitney, Gerald A. "The Composition and Construction of Monetary Aggregates." Economic Inquiry, October 1991, 29(4), pp. 752-61.

Thornton, Daniel L. and Yue, Piyu. “An Extended Series of Divisia Monetary Aggregates.” Federal Reserve Bank of St. Louis Review, November/December 1992, 74(6), pp. 35-52;

http://research.stlouisfed.org/publications/review/92/11/Extended Nov Dec1992.pdf.

Twain, Mark. The £1,000,000 Bank-Note and Other New Stories. New York: Oxford University Press, 1996.

Varian, Hal R. “The Nonparametric Approach to Demand Analysis.” Econometrica, July 1982, 50(4), pp. 945-73.

Varian, Hal R. "Non-Parametric Tests of Consumer Behavior." Review of Economic Studies, January 1983, 50(1), pp. 99-110.

Vickers, Douglas. Studies in the Theory of Money, 1690-1776. Philadelphia: Chilton, 1959, pp. ix, 313.

Walsh, Carl E. Monetary Theory and Policy. Third Edition. Cambridge, MA: MIT Press, 2010.

Williamson, Stephen and Wright, Randall. "New Monetarist Economics: Methods.” Federal Reserve Bank of St. Louis Review, July/August 2010, 92(4), pp. 265-302; http://research.stlouisfed.org/publications/review/10/07/Williamson.pdf.

Williamson, Stephen and Wright, Randall. "New Monetarist Economics: Models," in Benjamin M. Friedman and Michael Woodford, eds., Handbooks in Economics: Monetary Economics. Volume 3A. Amsterdam: North-Holland/Elsevier, 2011, pp. 25-96. 


\section{TECHNICAL APPENDIX}

\section{More on Index Number Theory}

In index number theory, a quantity index is a function of the quantities and prices of a set of goods in two periods. Diewert (1976a) defined the concepts of exact and superlative indexes, which Barnett (1980) applied to monetary data. ${ }^{37}$ In this context, the real stocks of a set of monetary assets act as quantities paired with their corresponding user cost prices. With this in mind, let $Q\left(\pi_{0}, \pi_{1}, \mathrm{~m}_{0}, \mathrm{~m}_{1}\right)$ denote a monetary quantity index, where $\pi_{0}, \mathrm{~m}_{0}$ and $\pi_{1}, \mathrm{~m}_{1}$ represent data for a set of monetary assets in two periods. Following Diewert (1993, p. 198), the quantity index is exact for the utility function $V(\mathrm{~m})$ if

$$
V\left(\mathrm{~m}_{1}\right)=V\left(\mathrm{~m}_{0}\right) Q\left(\pi_{0}, \pi_{1}, \mathrm{~m}_{0}, \mathrm{~m}_{1}\right)
$$

for every $\pi_{0}, \pi_{1}, \mathrm{~m}_{0}, \mathrm{~m}_{1}$ such that $\mathrm{m}_{i}$ maximizes $V(\mathrm{~m})$ subject to $\pi_{i} \cdot \mathrm{m} \leq \pi_{i} \cdot \mathrm{m}_{i}$ for $i=0,1$. Thus, if the quantity index is greater (less) than 1 , it indicates that the utility function is increasing (decreasing) from $\mathrm{m}_{0}$ to $\mathrm{m}_{1}$. A quantity index is superlative if it is exact for a linearly homogeneous utility function, which can provide a second-order approximation to an arbitrary linearly homogeneous utility function (see Diewert, 1993, p. 204).

Diewert (1976a) also defined exact and superlative price indexes. A quantity index, $Q$, and a price index, $P$, satisfy weak factor reversal (Diewert, 1993, p. 198) if

$$
Q\left(\pi_{0}, \pi_{1}, \mathrm{~m}_{0}, \mathrm{~m}_{1}\right) P\left(\pi_{0}, \pi_{1}, \mathrm{~m}_{0}, \mathrm{~m}_{1}\right)=\frac{\pi_{1} \cdot \mathrm{m}_{1}}{\pi_{0} \cdot \mathrm{m}_{0}} .
$$

Following Diewert (1993, p. 206), a pair of indexes is superlative if either the quantity index is superlative or the price index is superlative and they satisfy weak factor reversal.

Chain-weighting can be used to facilitate comparisons over more than two periods. A chain-weighted quantity index, $V_{t}$, is a time series constructed from a quantity index number formula as follows:

$$
V_{t}=V_{t-1} Q\left(\pi_{t-1}, \pi_{t}, \mathrm{~m}_{t-1}, \mathrm{~m}_{t}\right) .
$$

The MSI are chain-weighted monetary quantity indexes, which are based on the superlative TörnqvistTheil quantity index number formula. An alternative would be to use the Fisher ideal quantity index, which is also superlative. ${ }^{38}$ Farr and Johnson (1985), for example, used the Fisher ideal index to construct their series. In principle, other superlative indexes could also be considered. Diewert (1976a) proved that the quadratic mean of order $r$ quantity and price indexes is superlative for all $r$. The Törnqvist-Theil and Fisher ideal indexes are special cases ( $r=0$ and $r=2$, respectively). Using two datasets, Hill (2006, p. 38) found that these superlative indexes can differ significantly from one another. His interpretation is as follows:

The problem is that, as the parameter $r$ increases in absolute value, the superlative price (quantity) index formula becomes increasingly sensitive to outliers in the price-relatives (quantity-relatives) distribution. Admittedly, the only three superlative indexes that have been seriously advocated in the index number literature all lie in the range $0 \leq r \leq 2$, where the superlative formula is relatively unaffected by outliers. Over this range, all the superlative indexes do approximate each other closely. Conceptually, however, the economic approach provides no reason for restricting the range thus.

Thus, the choice of which index number formula to use seems to be more consequential than previously thought.

\footnotetext{
${ }^{37}$ The reader is referred to Diewert (1993) for a detailed survey of index number theory.

${ }^{38}$ Both the Törnqvist-Theil and Fisher ideal quantity indexes have also been shown to have attractive properties even if the utility function is not linearly homogeneous (see Diewert, 1976a,b, and Diewert, 1993, pp. 211-13). Diewert (1976a, pp. 137-38) offers several reasons why the Fisher ideal index is preferable to other superlative indexes; among these is its consistency with revealed preference theory.
} 
